PHENOMENOLOGICAL INQUIRY INTO

PHOENIX RSING YOGA THERAPY

\author{
By \\ JENILEE SNEED \\ Bachelor of Arts in Psychology \\ University of Redlands \\ Redlands, CA \\ 2006 \\ Master of Arts in Counseling \\ Ball State University \\ Muncie, IN \\ 2009
}

Submitted to the Faculty of the

Graduate College of the

Oklahoma State University

in partial fulfillment of the requirements for

the Degree of

DOCTOR OF PHILOSOPHY

August, 2017 


\section{PHENOMENOLOGICAL INQUIRY INTO}

\section{PHOENIX RSING YOGA THERAPY}

Dissertation Approved:

Tonya R. Hammer

Dissertation Adviser

Hugh C. Crethar

John S. C. Romans

Julie Croff

Kami Gallus 


\section{ACKNOWLEDGEMENTS}

I would first like to thank my participants for their openness and vulnerability participating in this project. Thank you so much for everything you brought to each session and all of the work in between with journals, interviews, and data checking. Thank you for allowing me to hold space for you and witness you authenticity and for allowing our deeply personal encounters to be used for research.

Thank you to my partner, Tim, for all of your support throughout my doctoral training, for caring for our baby for endless hours while I worked on this dissertation, and for your assistance with the technical aspects of this project. I would also like to thank our families for their support throughout this time, both tangible and intangible.

Thank you to my advisor, Tonya Hammer, for all of our meetings, your encouragement, and your belief in my ability to ability to tackle an ambitious qualitative project within a limited time span.

Lastly, thank you to all of my committee for your feedback and support, and a special thank you to John Romans who has been supportive of all of my research endeavors beyond this project and my career in general. 
Name: JENILEE SNEED

Date of Degree: AUGUST, 2017

Title of Study: PEHNOMENOLOGICAL INQUIRY INTO PHOENIX RISING YOGA THERAPY

\title{
Major Field: EDUCATIONAL PSYCHOLOGY
}

\begin{abstract}
There is growing recognition within psychology and other disciplines that body experience may be as important as cognitive and emotional experience. However, psychology has few psychotherapeutic interventions to support the integration of mind and body within therapy. Phoenix Rising Yoga Therapy (PRYT) is a form of mind/body therapy that uses yoga posture, touch, and psychotherapeutic dialogue to facilitate growth and healing. The current study explored the phenomenological experience of four women who received five PRYT sessions. The following themes emerged from the data: mindfulness, self-awareness, mind/body connection, in-vivo experience of new behaviors, client directed, empowerment, and life changes. Phenomenological case studies were also generated for each of the participants. While these results are not generalizable, they offer interesting theoretical implications for embodied interventions and the use of touch in psychotherapy.
\end{abstract}




\section{TABLE OF CONTENTS}

$\begin{array}{lll}\text { Chapter } & \text { Page }\end{array}$

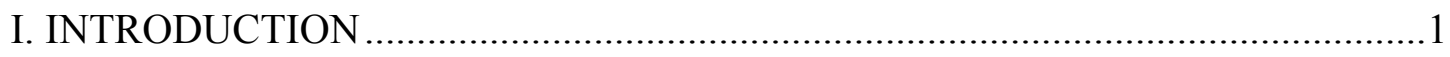

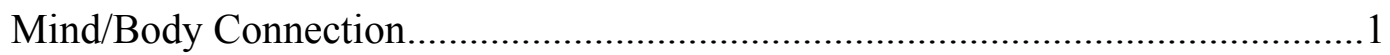

Yoga and Mindfulness ...................................................................................

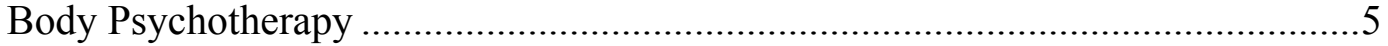

Phoenix Rising Yoga Therapy ………………...............................................

Current Study ………………………........................................................

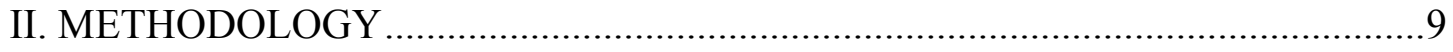

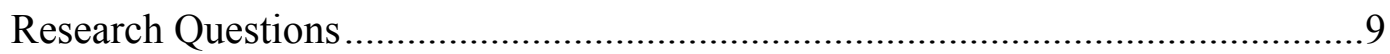

Rationale for Qualitative Research .....................................................................

Sampling and Participants ...................................................................... 10

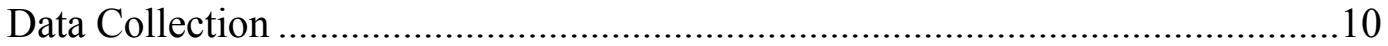

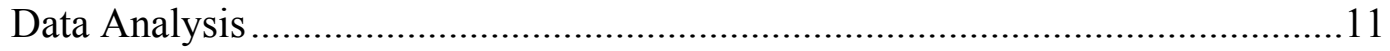

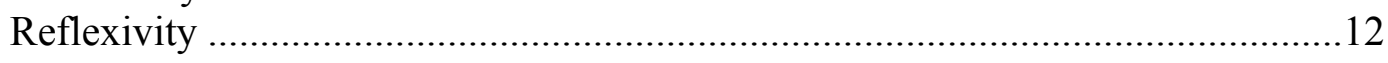

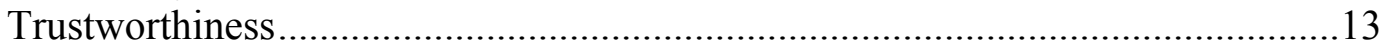

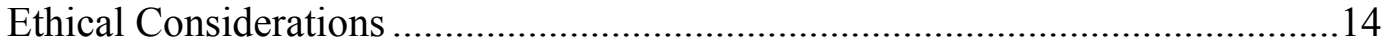

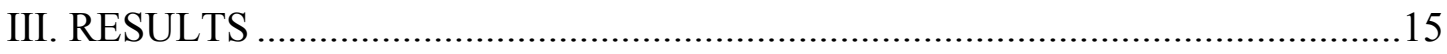

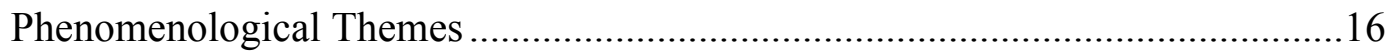

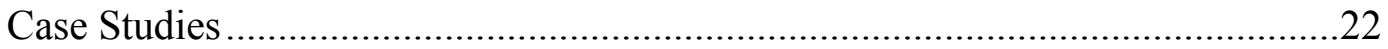




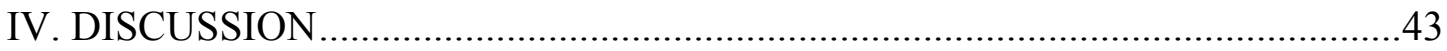

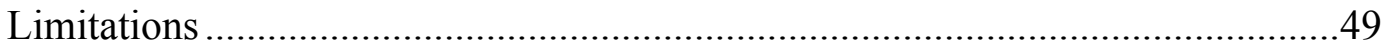

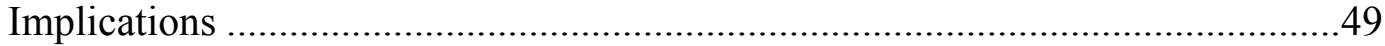

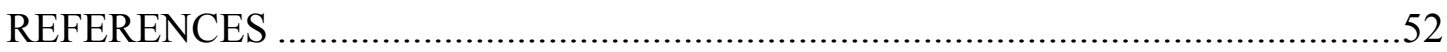

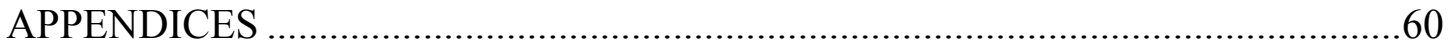

Appendix A: Extended Literature Review.....................................................6 60

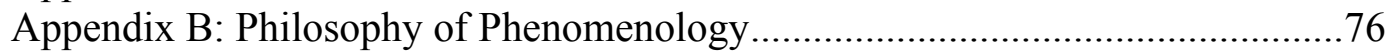

Appendix C: Phenomenological Interview Questions......................................79

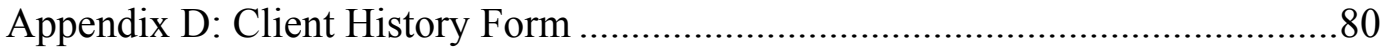

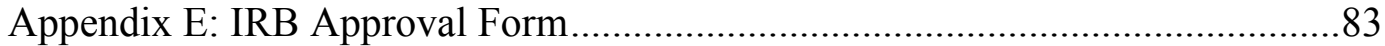

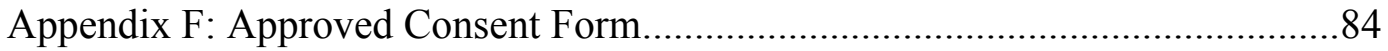

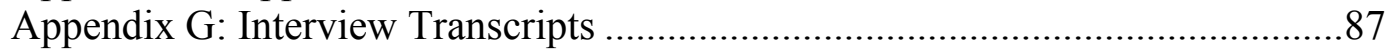




\section{CHAPTER I}

INTRODUCTION

\section{Mind/Body Connection}

Current research is increasingly recognizing the importance of mind/body connection, especially through studies on embodied cognition. Embodied cognition is the theory that the body and its experiences of the environment directly influence cognition (Leitan \& Chaffey, 2014). Flack (2006) discovered that in a sample of undergraduates, facial expression and body posture significantly influenced emotional experience. Similarly, Huang, Galinsky, Gruenfeld, and Guillory (2011) found that assuming a powerful posture increased confidence more than being given a powerful role in a social situation. Häfner (2013) likewise found that in a sample of undergraduates in the Netherlands that physical body experience influenced decision-making in persons with higher body awareness. While location specific populations limit each of these studies, taken together the literature shows that the body can influence how a person thinks and feels. Despite the growing support for a mind/body connection, in the psychotherapy world, quite often we remain a treatment of "talking heads" (Moodley, Sutherland, \& Oulanova, 2008).

This has led a growing number of people to seek out complementary and traditional 
healing practices (Moodley et al., 2008; Purohit, Wells, \& Zafonte et al., 2013). Purohit et al. (2013) examined data from the 2007 National Health Interview Survey and found that persons with neuropsychiatric symptoms, for example symptoms commonly experienced with posttraumatic stress disorder and other psychological complaints, were more likely to seek out complementary treatments than those without symptoms and that the likelihood of seeking complementary treatment was positively correlated with the number of neuropsychiatric symptoms experienced. The reason most commonly cited by the participants for seeking complementary treatment was that conventional treatments were not working. Participants also reported they typically did not discuss their alternative treatments with other providers.

Comparably, Mehling et al. (2011) found in their qualitative analysis of mind/body therapies that clients typically reported that they sought out mind/body therapy for specific concerns that traditional treatments had not been able to improve.

Educational psychologists have begun to study the phenomenon of embodied cognition and have begun to discuss changing the way children are taught in school (Claxton 2012; GoldinMeadow, Cook, \& Mitchell, 2009). Research found that children are able to retain learned math information when learning is paired with gesturing versus not gesturing (Goldin-Meadow, et al., 2009). Claxton (2012), in light of the embodied cognition literature, has urged the school system to expand the view of intelligence to include the body in education given the body's potential to influence thought and learning. However, similar to the psychotherapy field, this shift has been slow.

The transition from viewing the body and mind as separate to recognizing mind/body connection has been an arduous process in the Western world (Claxton, 2012; Levitan \& Johnson, 1986; Soth, 2005). Reasons for this may be found in the religious history of our culture with Mosaic Law and Christian beliefs in a metaphysical separation between the body and the mind and soul (Levitan \& Johnson, 1986), as well as in historical roots of Victorian and Puritan views of the body as unclean (Soth, 2005). Despite these past views, the importance for holistic 
treatment of persons can be illustrated by Fortsmann, Burgmer, and Mussweiler (2012), who found that when persons were primed with information on mind/body connection they were more likely to indicate greater health seeking behavior than persons who were primed with information expressing separateness of mind and body.

Mainstream psychotherapy has taken limited steps towards integrating the body into therapy. It has done so through the use of breathing and relaxation techniques (e.g. Brown, Gerbarg, \& Muench, 2013; Dolbier \& Rush, 2012; Lalande, Bambling, King, \& Lowe, 2012), using yoga as a treatment adjunct (e.g. Bilderbeck, Farias, \& Brazil et al., 2013; Froeliger, Garland, Modlin, \& McClernon, 2012; Kinser, Bourguignon, Whaley, Hauenstein, \& Taylor, 2013), and through specialized forms of body psychotherapy (e.g. Langmuir, Kirsh, \& Classen, 2012; Levy Berg, Sandahl, \& Bullington, 2009; Levy Berg, Sandahl, \& Bullington 2010; Rohricht, Papadopoulos, \& Priebe, 2013).

\section{Yoga and Mindfulness}

Yoga and mindfulness meditation have been found to be beneficial as an adjunct for a myriad of conditions. This includes populations such as cancer patients (Campbell, Labelle, Bacon, Faris, \& Carlson, 2012), veterans (Serpa, Taylor, \& Tillisch, 2014) and persons with depression and anxiety (Hofmann, Sawyer, Witt, \& Oh, 2010).

Many discourses on yoga propose that yoga changes a person's state of mind and way of relating to the world (Coster, 1972; Kowalski, 2001; Kraftsow, 2002; Levine, 2000; Mishra, 1972). For example, boys with Attention Deficit Hyperactivity Disorder (ADHD) who practiced yoga $(n=14)$ saw significant improvements in ADHD symptoms compared to a control group that did not receive yoga (Jensen \& Kenny, 2004). Women with depression have also found yoga to be beneficial. Kinser et al. (2013) randomly assigned 27 women with major depression to either a yoga or attention control group. Both groups showed significant improvement in depressive symptoms. However, women in the yoga group showed significantly greater decreases in ruminations compared to the attention control group. Additionally, yoga has shown 
to be beneficial for stress reduction among caregivers for individuals with dementia (Waelde, Thompson, \& Gallagher-Thompson, 2004), behavior control in a prison population (Bilderbeck et al., 2013), psychological stress in breast cancer survivors (Culos-Reed, Carlson, Daroux, \& Hately-Aldous, 2006), and reducing symptoms among individuals diagnosed with Obsessive Compulsive Disorder (Shannahoof-Khalsa, 2003).

Mindfulness meditation practices have led to improvements in both psychological and physical health (e.g. Carmondy \& Baer, 2008; Keune \& Forintos, 2010; Prazak, Critelli, Martin, Miranda, Purdum, \& Powers, 2012). Nyklíček \& Kuijpers (2008) randomly assigned 60 participants with symptoms of distress to either a Mindfulness-based Stress Reduction (MBSR) or wait-list control group. Those in the MBSR group showed significant reductions in perceived stress and significant improvements in positive affect and quality of life when compared to the control group. When mindfulness was included as a covariate, these results became statistically non-significant. This suggests that increases in mindfulness may mediate the positive effects of MBSR. Similarly, Carmondy and Baer (2008) found increases in mindfulness to mediate the relationship between meditation practice and improvements in psychological functioning.

There are also multiple neurocognitive correlates for mindfulness practices such as yoga and meditation. For example, age related brain differences have been observed between mindfulness practitioners and non-practitioners. In one study (Gard, Taquet, Holzel, de Montjoye, Brach,...Lazar, 2014), the brains of 47 middle-aged participants were compared. They were 16 Kripalu yoga practitioners, 16 Vipassana meditation practitioners, and 15 controls who had no experience with either yoga or meditation. Mindfulness, intelligence, and mental status were assessed and participants were asked to report frequency and duration of physical exercise and cognitive activities (e.g., reading, writing, solving puzzles). Brain imaging was collected on an MRI scanner and was analyzed using graph theory. While the yoga and meditation groups did not significantly differ from one another, both had significantly greater mindfulness scores than controls. The yoga and meditation practitioners also demonstrated decreased age related declines 
in fluid intelligence and MRI imaging showed that both of the practitioner groups had stronger small-world architecture with greater network integration.

\section{Body Psychotherapy}

Body psychotherapy is a broad term for a variety of psychotherapeutic approaches that seek to use the body as a vehicle for healing. These therapies help clients tune into body sensations, use kinetic movements to express and work through emotional content, and help clients become more self-aware of their internal environment (Burns, 2012). Body psychotherapies have shown some efficacy in the treatment of trauma survivors (Langmuir et al., 2013), persons with generalized anxiety disorder (Levy Berg et al., 2009; Levy Berg et al., 2010), and chronic depression (Rohricht et al., 2013). Langmuir et al. (2013) recruited 10 women ages 31 to 65 years with a history of interpersonal trauma to participate in 20 body-oriented group sessions. Participants showed significant improvement in body connection and decrease in dissociative experiences. Rohricht, Papadopoulos, and Priebe (2013) randomly assigned 30 patients awaiting treatment for chronic depression and dysthymia into a body psychotherapy group and a wait-list control group. Participants who received body psychotherapy showed significant improvement in their depressive symptoms and the control group displayed similar improvements after receiving the treatment as well. Levy Berg, Sandahl, and Bullington (2009) also found Affect-Focused Body Psychotherapy (ABP) to be as effective as treatment as usual for persons with Generalized Anxiety Disorder.

Unfortunately, all of these studies are limited by small sample sizes and reliance on selfreport measures. Despite the limitations and inability to generalize findings, these studies lend support to the belief in a mind/body connection and the potential efficacy of including the body in psychotherapeutic treatment.

\section{Phoenix Rising Yoga Therapy}

Phoenix Rising Yoga Therapy (PRYT) is a one-on-one form of mind/body therapy that integrates body movement, practitioner-assisted yoga poses, touch, and non-directive dialogue to 
facilitate client growth and change. It is different from typical Western-style yoga classes that may have an emphasis on fitness or form and deviates from other types of Yoga Therapy that seek to treat specific conditions (FAQS, 2014). It may be a viable option for clients seeking psychotherapy services with a mind/body emphasis. In the book, Phoenix Rising Yoga Therapy: A Bridge from Body to Soul, Micheal Lee (1997) the founder of PRYT, proposed his theory for the modality. He stated that PRYT allows the recipient to attune to a deeper level of knowing that she or he can then live from. This is done by becoming fully present to one's body and experience and then using that knowledge to promote learning and growth. The recipient learns to know and trust their own answers instead of seeking guidance from outside people or other sources. The body in PRYT acts as the vehicle to unlock inner wisdom and present moment experience so that the recipient can learn to live more fully from her or his own unique process (Lee, 1997).

Lee's theory has some similarity to the benefits of yoga expressed in The Yoga Sutras of Patanjali. The Yoga Sutras of Patanjali is the foundational text for Raja Yoga, which is a branch of Hinduism that focuses on the meditative concentration to still the mind and unlock the True Self. Today this text is often associated with the spiritual practice of the physical forms of Yoga such as Hatha. This text posits that when Yoga is truly experienced, one's awareness is able to rest in its true nature so that the True Self can be known and experienced (Patanjali, trans. 2002).

Previous research has examined the training of PRYT practitioners (Kokinakis, 1996) and the outcome of the manualized 8-week PRYT group called, “Turn Stress into Bliss" (Martin, 2010). Martin (2010) found that participants in the 8-week PRYT group significantly strove towards unattainable goals less frequently and reported significantly less stress than persons in the control group. This study is limited by its small sample size of nine participants who selfselected to be in either the experimental $(n=6)$ or the control group $(n=3)$. Furthermore, persons already attending yoga classes were targeted for sampling and this may have skewed results.

No studies to date have examined individual PRYT sessions. According to the PRYT website, PRYT helps clients increase self-awareness and self-acceptance and that through these 
increases, clients are able to change old behavioral patterns and beliefs (Why PRYT, 2014). Additional benefits listed in the PRYT training manual include: deep relaxation, greater emotional stability and mental clarity, empowerment and self-esteem, greater body awareness, and stress reduction (Phoenix Rising Yoga Therapy, Inc., 2008). Evidence to support these claims has been merely anecdotal.

\section{Current Study}

The current study sought to fill some of the gaps in the knowledge of PRYT through phenomenological inquiry. This approach allowed for an in-depth investigation into the lived experience of four PRYT clients. The in-depth case studies and uncovered themes shed light on the experience of receiving PRYT sessions from the perspective of the participants.

\section{Problem Statement}

Research indicates that the mind and body may not be as separate as once believed in Western psychology (e.g. Flack, 2006; Goldin-Meadow, et al., 2009; Huang, et al., 2011). There is growing evidence of a need for practices that address clients as holistic beings. Many clients are seeking complementary mind/body practices when traditional psychotherapy is not enough. Despite this evidence, most psychotherapeutic practices continue to address the body sparingly, if at all, throughout the course of psychotherapy. PRYT is one modality that may be a viable option for clients who desire an approach that focuses on all parts of self. However, not enough is currently known about PRYT's potential benefit and how it impacts clients.

\section{Statement of Purpose}

The purpose of this study was to explore the phenomenon of PRYT sessions through phenomenological inquiry of clients who receive PRYT sessions. This inquiry uncovered common themes that arose within sessions as well as case studies that display how the sessions impacted the clients and their lives. While the results are not generalizable, they offer a starting point to begin to explore PRYT on a broader scale and may give psychologists better understanding of the possible usefulness of PRYT. They also provide psychologists with 
experiential accounts that support the potential effectiveness of touch and body-based interventions in psychotherapy. 


\section{CHAPTER II}

\section{METHODOLOGY}

\section{Research Questions}

The purpose of this study was to explore the experiences of people who receive PRYT sessions. This included not only the experience within the sessions, but also how these sessions impacted the participants' perceptions of their day-to-day lives. The following research questions were addressed:

1. What are the clients' experiences of the phenomenon of PRYT?

2. How does receiving PRYT sessions impact the clients' lives?

\section{Rationale for Qualitative Research}

Phenomenological inquiry was used to explore the phenomena of PRYT. According to Van Manen (2014), a phenomenological research question is designed to improve understanding of experiences as we live through them and seeks to grasp the essence of an experience. That was the intended purpose of the current study: to understand the essence and experience of PRYT sessions for clients as they receive the sessions and live their day-to-day lives. 


\section{Sampling and Participants}

The Oklahoma State University Internal Review Board granted approval for this study. Participants were then recruited through fliers distributed via social media groups. Participant sampling was based on a typical case strategy (Creswell, 2013) and four participants completed the study. The number of participants was contingent on being able to gather enough experientially rich accounts to make possible powerful experiential examples of the phenomenon (Van Manen, 2014). Participants were required to be over the age of 18, not pregnant, with no self-reported risk for suicide or homicide, and no self-reported diagnosis of a psychotic disorder or active substance abuse disorder. Other criteria for participation were: interest in receiving body work that includes physical touch and dialogue, and an understanding that PRYT does not diagnose or offer a cure for any condition and that any change or growth experienced comes from within the client (Phoenix Rising Yoga Therapy, Inc., 2008).

Five participants responded to the advertisement and began participation in the study. One of these persons had to leave the study after receiving two sessions due to a family emergency that did not allow her to complete the sessions within the specified timeline. Her sessions were not included in the data analysis. The remaining four were all White heterosexual cis-gender females residing in Stillwater, Oklahoma. Participants ranged in age from 28 to 54 years.

\section{Data Collection}

In order to increase the robustness of this study through crystallization, data was collected from four sources (Tracy, 2010). First, participants completed intake paperwork that included demographic information such as age, gender, employment status, health history, and reasons for seeking out PRYT sessions. Second, participants received five PRYT sessions, with at least one week between each session and no more than two weeks between sessions. All sessions were video recorded. Next, participants were asked to journal after each session. A composition notebook was provided to each participant before sessions began. Participants were given with 
the prompt to write a reflection after each session about their experience in the session and any way(s) that experience seemed to be affecting their lives. They were told that they may also journal more frequently if they chose. Lastly, a second year doctoral student in the Counseling Psychology program at Oklahoma State University interviewed participants after they had completed their five PRYT sessions. Interviews were audio recorded and transcribed by me. Semi-structured interviews lasted one-hour or less and included probes used as needed to better elicit concrete stories that express the lived experience (Van Manen, 2014). Interview questions and transcripts are provided in the Appendices. All collected journals and client intake paperwork were stored in a locked box within a locked office that only I have access to. Digital data was stored on a password-protected hard-drive in the locked office and on a shared campus research drive that only designated persons had access to. The data will be destroyed five years after publication of the dissertation. Intake paperwork will be destroyed seven years after participants stop receiving PRYT sessions from me.

The initial meeting and all sessions took place in my office in Stillwater, OK. This office is a rented private room in a shared suite within a multi-use complex. It is used for my PRYT private practice. Phenomenological Interviews were conducted in a private room within my doctoral department's practicum clinic.

\section{Data Analysis}

Textural data was analyzed using phenomenological thematic analysis as described by Van Manen (2014). This form of thematic analysis does not rely on a rule bound coding system but is instead a three-step process meant to elicit the meaning of the lived experience. Van Manen also recommends than non-text data be analyzed in ways that make sense for the type of data and that do not take away from the ability to understand the life-world as much as possible.

Phenomenological thematic analysis was modified slightly for video recorded data. The steps of analysis were as follows:

\section{Wholistic Reading}


Session videos, journals, and interview transcripts were attended to as whole pieces in order to ascertain the phenomenological meaning and main significance found in each piece. This meaning was expressed by formulating a single phrase for each piece.

\section{Selective Reading}

Each piece of data was then read or viewed several times in order to identify the parts or statements that seem particularly essential to understanding the phenomena. These parts were written down. Using these parts, I sought to capture the phenomenological meaning using reflective descriptive-interpretive paragraphs supported by the highlighted phrases and/or descriptions of what is occurring in the video including quotes from the dialogue, if applicable. These paragraphs were then compiled and transformed into phenomenological case studies for each participant

\section{Detailed Reading}

Lastly, each piece of data was read thoroughly sentence by sentence, or viewed moment by moment. For each piece of data, I identified what the sentence/moment may reveal about receiving PRYT sessions in order to further understand the phenomenological meaning of the experience.

After all of the data was analyzed as outlined above, themes were reduced and synthesized into reflective phenomenological themes presented in paragraphs with supporting quotes from the data (Van Manen, 2014).

\section{Reflexivity}

I am a certified PRYT practitioner and firmly believe in the ability of this modality to lead to insight and growth in the lives of those who receive it. Additionally, I have received sessions myself and experienced greater and more rapid healing through PRYT than I did with traditional psychotherapy. However, I have also worked with a variety of clients and each has reported her or his own unique experience based on what she or he desired to receive from PRYT and how she or he approached the sessions and chose to integrate the experience into her/his life. 
In addition to my PRYT training, I have a Master's in Counseling and am a doctoral candidate in Counseling Psychology. I have been a practicing counselor for seven years and view clients from a primarily person-centered perspective. PRYT practitioners are not required to have mental health training and it is possible that my psychotherapy background influences my yoga therapy practice. Although I adhere to the PRYT method and it is essentially non-directive, my experience in practicing psychotherapy informs my use of the dialogue interventions within PRYT and it also influences how I perceive and understand my PRYT clients.

I provided all of the PRYT sessions to the participants of this study. The non-directive nature of the PRYT approach limited my ability to influence the participants within session. In order to provide further control for my bias, I engaged in reflective journaling throughout the course of this project where I reflected on my own process in each PRYT session, and throughout data analysis (Glesne, 2011). I also met regularly with my dissertation advisor, who acted as internal auditor, through the data collection and analysis process to discuss sessions and receive feedback on the case studies and identified themes. Throughout these meetings we discussed how my mental health training influences my perceptions of the participants, the ways PRYT differs from psychotherapy, and how I remain authentic to the PRYT method despite my additional training. We reviewed various sessions for each of the participants during the process of data collection to insure that I was consistent throughout the sessions in approach to each participant.

\section{Trustworthiness}

A certified PRYT practitioner who I did not already know was sent a random sample of recordings of sessions to verify for authenticity. She viewed one session from each participant and declared that the sessions provided were authentic PRYT sessions (G. Boyd, personal communication, December 14, 2015).

Member checking (Tracy, 2010) was used throughout data analysis. Each participant was given a copy of their case study and was asked to verify the content and edit at will in order to make it better fit their experience. Each participant stated that the case study accurately 
represented her experience and none offered changes. My reflective journals were also provided to participants in order to create greater transparency between researcher and participants.

A professor from the Social Foundations department at Oklahoma State University who teaches courses on qualitative research externally reviewed the identified themes in order to insure trustworthiness and provide another form of crystallization (Tracy, 2010). The external auditor was provided with the raw data, the information compiled at each step of data analysis, the verified case studies, and my own reflective journals. She concluded that the themes demonstrated internal homogeneity and external heterogeneity and reported that the data analysis was thorough, systematic, and coherent (T. Shilling, personal communication, March 28, 2016).

After the external review, participants were provided with the across data themes identified from their specific sources of data and invited to identify if they found the themes to be true and accurate for their experience. All participants verified their respective themes and reported agreement with the findings.

\section{Ethical Considerations}

PRYT has the potential to unearth emotionally distressing information and awareness (Phoenix Rising Yoga Therapy, Inc., 2008). Before beginning the PRYT sessions, I informed each participant of the risk of emotional distress and discussed the coping resources they use including their current support system (Phoenix Rising Yoga Therapy, Inc., 2008).

Participants shared sensitive personal information during their sessions, in their journals, and in their interviews. All data has been de-identified in the final write-up. The names used in the reporting of results are pseudonyms chosen by the participants. Files that were shared with the participants and the PRYT professional who verified authenticity were encrypted and placed in encrypted folders. The external reviewer was granted access to the shared research drive in order to audit the files.

This study was approved by the Institutional Review Board at Oklahoma State University before participants were recruited. 


\title{
CHAPTER III
}

\author{
RESULTS
}

All of the PRYT sessions followed a similar format and clients were encouraged to keep their eyes closed throughout the session. They began with an intention setting meditation. In this meditation clients are invited into an embodied experience of themselves in the present moment and asked to find an intention based on what they are observing about their present experience. I typically initiated touch for the first time after intention setting by placing hands on the client. One common method of initiating touch was to place the palm of one hand on the center of the client's back and the finger tips of the other hand on the center of the client's chest. Clients were asked to move my hands if they wanted them in a different spot. Dialogue typically consisted of me asking, "what's happening now?" and the client responding with whatever they may notice in the moment. I then repeated the client's words to her or may ask the client to "tell me more." Clients were invited to experience various poses that may resemble traditional yoga poses or may be any position or movement that reflected what was being discussed in session. For example, a client talking about balance was invited to sit on a balance ball. Postures were typically supported by props or the practitioner's body. Sessions ended with another meditation that invited the client to reflect on the session and relate it to her life. This format is consistent with how 
PRYT practitioners are instructed to format sessions (Phoenix Rising Yoga Therapy, Inc., 2008).

\section{Phenomenological Themes}

\section{Mindfulness}

Mindfulness, in the form of the present moment observation of self, was a theme that permeated each of the PRYT sessions and is perhaps best encapsulated by the primary PRYT intervention of the question, "what's happening now?" The practitioner asked the clients throughout each session to notice their present moment experience through the repeated asking of this question. The practitioner also began each session with an intention setting meditation by inviting the clients to notice their breath, their body, their thoughts, their feelings, and their spiritual self (whatever that may mean for the client) in the present moment. Mindful observation of self was further reinforced by the practitioner repeating the client's spoken words back to them.

Amber noticed the mindful tone of PRYT in her first session, "I don’t stop much during the day to be aware... I didn't realize how tight they [her shoulders] were... I stiffen up a lot without realizing that I do." Sally also reflected on this in her first journal entry, "I very much liked the "closed eyes" idea- I do that a lot with my yoga practice and feel like it fits with inner work, helps me concentrate and let go and makes the practice more meditative."

Mindfully attending to self in session often led to observing subtle shifts in their experience. For example, Elizabeth stated, "I'm just concentrating on my breath and feeling it go from shallow to more deep breathing." Participants also noticed that there were many different aspects of the present moment to which they could choose to attend. Katie especially noticed that she could attend to her chronic pain and discomfort or that she could choose to notice other sensations, "Shifting my focus a little, noticing what I can feel with the movement instead of on the lingering pain in my upper back."

\section{Self-awareness}


The participants generated insight in session. While they observed their present moment experience, they often made connections to how these thoughts, feelings, and behaviors are demonstrated in their day-to-day lives. When exploring her fear of injury, Amber gained awareness of the secondary gains that this fear also serves, "I think I also use my hip as an excuse to not do a lot of things that scare me physically. In fact my fear of failure, if it's my hips fault I can't workout then it's not my motivation." She also increased her awareness of how pervasive her worry was, "I knew I was worrying about my children a lot but didn’t realize how much of my mind was taken up by that space." Katie gained awareness into the large role that her pain was playing in her life and sense of identity, "I feel like the pain is there so often that I dedicate all my faculties to it and then when it's gone I don't know what to do with myself. I don't know how to be me if I'm not hurting...This isn't the person I wanted to be...I don't know how to deal with and control the pain and still be me. I don't know where to go from here...I'm tired, tired of hurting, tired of not knowing how to deal with it... I feel like I realized that I'm in denial...about how the pain affects me and how I let it affect other people."

Growing self-awareness is also supported by the practitioner's invitations to reflect on behaviors observed in session. In Elizabeth's third session the practitioner asked, “Tell me more about waiting for my invitation to move out of an uncomfortable position.” After a pause, Elizabeth responded, "You get in the habit of doing a lot of things and don't really think about it because it's a habit. A lot of times it's easier to just follow the directions than to do what I want to do or think I should do.“ The use of touch in sessions was another key intervention that supported Sally's growth in self-awareness. In her first session while in a pose where she was leaning back with her body fully supported by the practitioner's she began to cry and stated, "Just wish that I had that kind of mother...I wasn't held or touched so, I met a lot of people that their dead sibling was the wrong one that died and that's how I felt too... and my mother felt that way," and later reflected in her journal, "I said that I wasn't touched or held as a child that I can remember. That is beyond unfair. I think that's why I wept- even though I have a physically 
loving relationship with my husband and kids now, I still long for and deserved one with my mother."

\section{Mind/Body Connection}

Although dialogue is present throughout PRYT sessions with the practitioner regularly asking, "what's happening now?" and inviting the clients to, "tell me more" about what they are discussing, the body is an integral part of the experience. Clients move their bodies throughout the session either through their own volition or with assistance from the practitioner. They are also invited into an embodied experience by being asked to notice their breath and their body at the opening of session. During the sessions clients often talk about the physical sensations they are observing and relate them to their emotional and cognitive experience.

In many of Katie's sessions, mind and body connection were of paramount focus, "physically it was almost painful but as the tension releases, mentally I feel a little lighter. Like those two things are correlated...wondering what would happen if I relaxed the muscles, wondering if this is even where the muscles should be, wondering if tension or worry has caused them to find a home in a different position." Amber also noted that the sessions helped her understand the interconnectedness of mind and body, “I didn't realize what effect my thoughts were doing to my physical self. I kind of thought that they were two separate things and then I realized how much my fear and anxiety over everything was negatively effecting my body."

At times, the practitioner will also position the client's body to reflect what the client is talking about. Sally reflected on this in her journal stating, "We opened with an intention- I said 'being open' because I've got so much change ahead and need to be open to whatever unfolds because it's all good and keeps becoming better. She had me lie back on bolsters which felt amazing (and open!).” The practitioner also may invite the client to notice thoughts and feelings associated with different body parts as part of a body scan. During a body scan, Elizabeth observed her thoughts and feelings associated with her stomach, "My lower abs hurt and that reminds me of the fact that I had to have two c-sections and so my abs are constantly, I've had 
constant issues with my abs with them not holding my stomach up as easy as they used to...it just makes me so angry and sad because I can't do a lot of things I used to as easily, they're really hard." In-vivo Experiences of New Behaviors

The experiential nature of PRYT creates an opportunity for clients to explore new behaviors in session. This was especially present in Amber's sessions. She engaged in many physical postures that were frightening due to past injury, "I guess I've always, since my hip's been hurt, I've always been afraid to do anything with my back. Afraid it will make it worse, but it's not...noticing that it actually feels pretty good...noticing that more of my fears are probably unfounded." Similarly, Katie noticed that a novel experience in session brought more peace than her typical way of being, "Trying to let go of the idea that I have to be in control of every single detail of my life... when I relax and let you control the movement it feels better and it hurts less, maybe if I can use that principle with other things and let go of some control it won't be as hard to maintain a more peaceful positive outlook."

The majority of Sally's time in session was an experimentation with new behavior. Allowing therapeutic touch was difficult for her and not something she had experienced previously in her life, "Well if I can get a good recommendation from someone...I might get a deep tissue massage. I don't know, just saying it feels kind of creepy but I might because of this [PRYT], you know, just being willing to go past where I'm afraid [by allowing touch in session]."

\section{Client Directed}

Clients choose what is explored in session both physically and mentally. Clients are informed from the beginning that all of the verbal interventions (i.e. "what's happening now?" "tell me more") are invitations and that they always have the choice to remain silent. They are also encouraged to self-direct the movements either by spontaneously choosing a pose, readjusting as needed, or communicating how deep they want to go into a stretch. In PRYT, this 
is called choosing your edge. The edge is any place that may feel slightly uncomfortable to be in but still safe (Lee, 1995). Elizabeth often self-directed away from distressing material, "I'm going to try to set aside the feelings about my abdominal muscles and body image so that we can move on to the next part of the body scan...I just don't see the point in dwelling on it." While Katie often chose to explore uncomfortable areas, “There's an edge of pain (practitioner asks, "an edge you want to stay with?”) Yeah...I feel like I am learning my boundaries...another way to know what to expect to stay in control.”

The practitioner also does not follow-up on content from previous sessions in order to allow the clients to work with the present. In her journal, Sally noted, “There's no continuity between sessions because it's not the job of the 'therapist' to follow-up or ask questions- but it's weird because I think 'hey did I follow through with that intention from last week?' But it's also a clean slate and refreshing to not 'fail' at something when it wasn't a good fit. Also to not have the stereotypical 'angry therapist' who is going by their notes instead of looking at who you really are...And if I want some continuity, I can make some of my own to renew the former session's intention for this one." Sally also often chose to remain silent in session, "I didn't always share what I was, clearly I couldn't share every thought I had, but I didn't share what was like my intention, I didn't do that."

\section{Empowerment}

In the sessions and their journals the clients often expressed hope that change is possible and felt optimistic that they would have the ability to create the positive changes they desired. Katie stated in her final session, "I make my own decisions...I am in charge of my decisions...I have to take an active role in making decisions that are good for me" and Sally noted in her journal, "[Yoga therapy has] affirmed my innate belief system to heal from within. I may patiently wait for the answers but they're all coming from me! That's so deep and profound. My own knowing truly is...the best fit. If I am allowed to have time, quiet, and reverence shown to 
me, I will thrive and grow. I will be working on me as long as I'm alive. I'm excited about that. The future is so bright."

During the ending meditation the practitioner also invites clients to find an "I statement" relating to the session. This invitation often led to an empowering statement. Amber created the "I-statement," "I am stronger than I think I am," and Elizabeth created, "I have the strength to face it."

Often empowerment also coincided with the other themes of mind-body connection and in-vivo experienced of new behaviors. For example, by trying new behaviors with her body in session, Amber expressed, "Realizing I have a broader range of motion than I think I have. Feeling stronger. I'm actually trying things that scare me." Katie also noted, "I feel like I'm being stretched in more ways than just physically, like I have the capacity for new growth.”

\section{Life Changes}

Each of the clients noted several life changes that they attributed to receiving the PRYT sessions. At the end of each session in the final meditation clients are asked to identify a concrete action step that relates to what they noticed in session. In her first session, Katie stated that she would try a muscle relaxation exercise to help her manage her pain. She reported engaging in a progressive muscle relaxation (PMR) in her journal and stated, "After trying PMR by tightening and releasing certain muscle groups, I felt calmer. I fell asleep faster, and still had no pain.”

Elizabeth stated in her exit interview that it has helped her be more mindful in her day-today life, "it's made me more mindful not only of what I'm doing or how I'm doing it but what I'm thinking about because a lot of times I will either overthink something or underthink something and so it's made me try to really be more conscious of that middle road."

Amber noted several changes that she began to enact in her life as early as the second session. In her second session she stated, "I realized what a huge space they [her anxieties] occupied in my mind. I'm making a conscious effort to realize how often I think of them and then to just let them go and not dwell and focus. But I have to make a conscious effort every day." 
In a journal entry following her last session, Sally wrote, "I've been missing my meetings...for Yoga Therapy- it was a transformational experience...the way it reaches inside you in such a unique way. I can see so many benefits. I'm open (now) to seeking massage therapy when before the trust just wasn't there- and I feel like I tried something new and outside my comfort zone."

\section{Case Studies}

In the following section, case studies are presented for each of the four participants. Quotations from the participants have been edited to exclude verbal phrases such as um and uh. Amber

Amber was a 32 year old, White, heterosexual female employed as a hair stylist. She was interested in and excited about receiving PRYT sessions because she hoped it would help her with her anxiety. She had been dealing with anxiety for much of her life and it highly influenced her relationships with others, particularly her children, as well as her ability to take risks. One particular source of anxiety was engaging in any form of exercise since breaking her ankle and injuring her hip two years prior. Amber expected a calm, meditative practice and was surprised by the physical nature of the work.

In her first session, having her eyes closed and observing herself in the moment allowed Amber to have an authentic encounter with herself, "I hide behind a big veil of humor, it's nice to let it down." Letting her veil down allowed her to acknowledge the pervasive worry she was experiencing about her children as well as her sadness over her daughter's hearing loss and the impact that her anxiety has on her children. Tears erupted within the first 15 minutes of this session as she acknowledged the thoughts and feelings she had been holding at bay. Amber continued to observe the flow of thoughts, emotions, and sensation throughout the session and began to notice how her thoughts impacted her body, particularly the manifestation of fear as physical tension, "Trying to relax my body... I stiffen up a lot without realizing that I do." In her journal later on that day, Amber acknowledged the relief she felt from exploring her fears and 
giving herself permission to let them go. The experience in session left her feeling hopeful and motivated that change is possible.

At the start of her second session, Amber reflected on changes she had been trying to make since the last session, "I've really been trying to focus on not stressing and really trying to focus on the physical toll all the stress took on my body. I think it's slowly getting better the more I become aware of what I'm doing to myself." She also discussed significant life occurrences such as going to say goodbye to her grandmother who she most likely would not see again before her grandmother dies. Although there was no prompting to notice anxiety, by observing her present moment experience, the patterns of thought and behavior that she routinely engaged in became apparent.

Amber's anxiety was so pervasive at this point in her life that it again became the central focus of the session. The embodied experience created in the sessions allowed Amber to be present with her fear about injury and to explore the ways her reality did not match her fears, "I guess I've always, since my hip's been hurt, I've always been afraid to do anything with my back. Afraid it will make it worse, but it's not...noticing that it actually feels pretty good...noticing that more of my fears are probably unfounded." Throughout this session she faced her fear of injury and utilized her breathing and self-talk to cope with her fear response, "relaxing and slowing my heart down after, very nervous with my hip, and accepting that there's nothing wrong, my fears are unfounded, I can relax again." She also gained insight into the embodied experience of her fear, which for her manifested as shaking in her legs when the practitioner was moving them and breathing shallowly. She practiced tolerating her body's fear response, "allowing my leg to shake instead of fighting it...letting it release by allowing my body to feel the fear." The ability to face her fear and to learn that she could accomplish some physical activity safely, left Amber feeling empowered, "feeling very proud of myself. I usually allow any small fear to stop myself from doing anything." The empowered feeling endured post-session when the pain she had feared might manifest later in her hip never did. 
In session three, the body-based approach of PRYT gave Amber a unique opportunity to explore her relationship with her body. She acknowledged her feelings towards her body, "I think my weight is a sensitive subject with me since I was a slimmer child and young adolescent and never had to deal with it. I've been gaining and losing 50lbs. seems like every year with my children...it's hard for me, a lot of shame." It also allowed her to have new experiences with her body by trying movement she would typically avoid doing, "realizing I have a broader range of motion than I think I have. Feeling stronger. I'm actually trying things that scare me," and to acknowledge the positive gains experienced from her anxiety about physical injury, "I think I also use my hip as an excuse to not do a lot of things that scare me physically. In fact my fear of failure, if it's my hips fault I can't workout then it's not my motivation."

In this session, I led the client in a two-part dialogue. In this intervention, the client is invited to engage different parts of her body in a conversation. This created an opportunity for Amber to further re-evaluate her relationship with her body, “ 'Its [Amber is speaking from her hip] thoughts are in absolutes, can or can't, but it's saying maybe there's a grey area.' Amber then speaks to her hip from a part of her body that feels opposite, 'Just calm down and accept yourself more.' Hip responds, 'I'm worried it will never happen but I'll try.' This experience led to a commitment to change her relationship with her body, "I realized I was angry with myself for my weight gain but I think I can forgive myself."

Amber had been exploring her anxiety throughout her previous sessions and during the fourth session realized the full impact that anxiety has on her body. She had developed an ulcer due to anxiety about her daughter and had to leave session to vomit twice. After vomiting the first time, Amber tried to move on from this experience, "starting to realize I'm ok again. Trying not to worry about my daughter or my ulcer."

However, PRYT invites the client into an experience of the present moment and Amber was unable to distract herself from, or to deny, the presence of her fear, "I know it doesn't help to think about it but it [the worry about her daughter] keeps popping up in my mind." She was also 
unable to ignore her physical discomfort. Being present with her physical and cognitive experience led to increased awareness, "vocalizing my fears helped me realize it's me, not her, that's worried;" "the more I worry, the worse my ulcer gets," and a commitment to overcome her anxiety, "I think I must get over my fears, for my daughter and my health.” In her journal later that day, Amber acknowledged the power that anxiety currently had in her life, "I had thought my anxiety was getting better but since the start of school was fast approaching and I was worried sick abut my daughter. It was really a wake-up call to get my anxiety in check.”

Amber's final session took place two weeks after session four. Her ulcer had resolved at this time and her daughter had successfully started school. In all of the previous sessions, Amber had been fearful about her daughter starting school due to the possibility that her daughter may be bullied for her disability. After the removal of her primary stressor, Amber was able to increase her ability to mindfully observe physical sensations and thoughts in session. This allowed her to not just be aware of her fears but also to use her body as a tool to dispel anxiety, "stretching I can visualize my anxieties, the good and the bad, pulling away from me" as well as attend to her thoughts mindfully, "trying not to give my negative thoughts as much of a voice in my head anymore. Any time a negative thought comes in I like to hear it and now I'm trying to let it go and not let it consume me." As with previous sessions, Amber continued to explore anxiety provoking behaviors and to experience success in the new behaviors. Her decreased stress also enhanced her ability to use positive self-talk to cope with the fear, "trying to give my body the message that it's ok, it's ok to try new postures and movements. It will be ok, I'm not at risk of injury." At the end of the session, Amber expressed confidence in her ability to try new things and manage her anxiety, "I am stronger than I think I am." In her journal following this session, she expressed a commitment towards continued change, "I am going to continue to meditate and work on my anxiety. I am going to try and accept myself and address my fears over injuring myself and being an inadequate mother." 
Amber's follow-up interview took place seven weeks after her last session. She reported that the meditative nature of the therapy increased her awareness of herself and helped her become less reactive to thoughts and sensations, "I became much more aware of negative thoughts... when I realized what a huge space that I gave it [negative thoughts] in my mind. I was able to address them and move on much more quickly than just thinking about it over and over all day." The combination of dialogue and physical postures also showed her how her mind and body are connected, “Well, the most I remember is how I didn't realize what effect my thoughts were doing to my physical self. I kind of thought that they were two separate things and then I realized how much my fear and anxiety over everything was negatively effecting my body... I haven't had an ulcer or a gout attack since I started. I used to have them [gout attacks] about once a month.” The journaling after sessions also appears to have increased awareness, "Well see like when I would be writing and I would talk about how I felt and then I was like oh I did kind of feel like that. I guess I didn't really feel that it, I didn't realize it at the time." In addition to an improvement in her physical health of no gout attacks, she has also continued to make positive life changes including the commitment to meditate stated in her final journal, "well I continued to meditate after we stopped and that is really, it's really helped me to control my thoughts, my negative thoughts and anxiety and fear. And I actually started exercising again, which was a big deal because I hadn't since I broke my ankle a couple years ago.”

\section{Elizabeth}

Elizabeth was a 32 year old, White, heterosexual female. She was a mother of four children under age five and a $\mathrm{PhD}$ student. As such, she had very little down time and was often running on less than adequate sleep. This, coupled with anxiety, that she has been receiving psychotherapy for, made it difficult to receive the sessions and stay present at times. In her initial paperwork, Elizabeth reported that she hoped the PRYT sessions would help her renew her yoga practice. 
Elizabeth was nervous for her first session, “I'm anxious and nervous about all the things going on and I'm anxious and nervous about what we're going to be doing in the first session because it's new...I always get those nervous butterflies when I do something new and when I don't know what's going to happen and there's no predictability." This nervousness permeated as she focused on observing thoughts and sensations without exploring more deeply. Despite this, she was able to make meaning at the end of the session, "I just noticed the randomness of my thoughts...ever since the babies arrived things have been random and without routine. It's been a struggle to not have a set routine and I think about that most days, about establishing a routine for the family and getting away from randomness and a lack of schedule." In her journal following this session, Elizabeth further reflected on her discomfort in session, "I enjoyed the session overall, though, I was a little distracted by the repeating of my statements. I felt embarrassed sometimes, having my own thoughts repeated to me...there is always a feeling of needing to hold back when I speak to people. I am always worried that they will think that I am crazy or abnormal in some way, especially when it comes to my own thoughts, this probably played into the awkwardness of the repeating statements."

In her second session, Elizabeth noticed that PRYT creates a space where she can slow down and relax. This was very different from her normal day-to-day life, "I'm just concentrating on my breath and feeling it go from shallow to more deep breathing... just trying to calm everything down from the average day pace which is very fast compared to in here where everything is much slower." This session also put Elizabeth in more familiar terrain, "we did more poses that I expected such as child's pose and cobra." The familiarity couple with the slow pace of the session created a relaxed environment leading to sleep, "my only problem was that I was tired. I actually fell asleep during our session. I guess I was pretty relaxed during our work... I enjoyed the session, despite falling asleep. I liked the change of poses this time around.” Experiencing the calmness that ensues from slowing down and noticing the here-and-now showed 
Elizabeth that she can cultivate this in her outside life as well, "The idea that slowing myself can calm me down which transfers to my children."

Two patterns began to become apparent to me by session three. The first was that Elizabeth would often mention discomfort in poses but would not take steps to take care of her body without prompting. When asked to reflect on this pattern, Elizabeth stated, "You get in the habit of doing a lot of things and don't really think about it because it's a habit. A lot of times it's easier to just follow the directions than to do what I want to do or think I should do." The other pattern was less evident at this time but was starting to emerge. As Elizabeth became more comfortable in the sessions, she had an increased ability to connect events in the session to her outside life, "It seems like I'm making it [the pose] harder than it could be and as has been demonstrated to me in the last couple of weeks I tend to do that in a lot of areas of my life. And I'm just wondering if I'm taking the harder route instead of doing something easier." However, self-consciousness persisted and inhibited deeper exploration at many opportunities. Most invitations to delve deeper into an issue were met with superficial explanation and/or a shift back to observing physical experience in the moment. She also noted in her journal the difficulty she experiences when trying to stay present with herself, "In my daily life, I do about 10-15 minutes of meditation, anymore than that and I get anxious about all of the things I should be doing."

The pattern of connection and distraction observed in session three persisted throughout subsequent sessions and was most vividly evident in session four. In this session, she was invited to do a body scan. Slowing down and being present with her body allowed Elizabeth to get in touch with emotions she was still holding about her stomach and previous Cesarean sections. She stated through anger and tears, "my lower abs hurt and that reminds me of the fact that I had to have two C-sections and so my abs are constantly, I've had constant issues with my abs with them not holding my stomach up as easy as they used to...it just makes me so angry and sad because I can't do a lot of things I used to as easily, they're really hard. Whereas on a daily basis I hear all my other friends, 'oh I need to lose 10-201bs., oh my stomach is disgusting' when 
they're a size six or eight and I'm like, 'no you don't get to complain about that, I don't care if you have body issues, you can't complain that you have a small tummy pooch, it's not fair that you still look fantastic and I'm gigantic and look horrible and nasty and can't really do a whole heck of a lot about it without paying for elective surgery.' And that just, I'm getting flack from people saying, 'well you just need to exercise' and I'm like, 'well screw you because I can't, try having my chaotic schedule and all the ab issues, the separation of the abs so that you can't do crunches and stuff like that.' So like I said it's a really sore subject." After this emotional expression, Elizabeth swiftly changed the subject and refocused on her physical sensations stating, "one of my toes has fallen asleep." She then stated, "I'm going to try to set aside the feelings about my abdominal muscles and body image so that we can move on to the next part of the body scan...I just don't see the point in dwelling on it." Despite her desire to not focus on these thoughts and feelings they continued to resurface. At each resurfacing, Elizabeth would shift her focus and change the subject again, "I used to play [tennis] all the time and then I had my older twins and then because of the C-section it was difficult to play. I tried playing for a while but my center of gravity was greatly affected and I had quite a few accidents on the court... I fell over and got hurt, so I stopped playing. (Elizabeth yawns) ouchie! Oo don't yawn in the middle of that chest stretch." At the end of session, Elizabeth acknowledged what a huge issue this still was for her, "The other thing that stands out is how emotional I am about my abs, I didn't realize I was so upset, I thought I had moved past it...it impacts my physical wellbeing on a daily basis, as well as my body image and how I feel about my kids and how I feel about how others see me...it infiltrates almost every aspect of my life so I probably should address it." In her journal following this session, she identified some lifestyle changes she would like to make with diet and exercise to help her feel better about her stomach.

In session five, although Elizabeth continued to engage in her pattern of moving away from emotionally charged material, "it seems like I struggle all the time with a variety of things (I say, 'tell me more,' client is silent and then loses her train of thought)," other small changes 
began to manifest in this session. In this session Elizabeth became more self-directive with her body movement. There were several instances of her choosing a posture or modifying a posture as needed for her comfort without prompting. She also frequently in sessions expressed imagery filled thoughts. For example in session one she stated, "I had some random visions of a wounded wolf, I don't know where that came from." These types of thoughts continued but she was now able to better relate those images to her life, "For some reason I was thinking about a cruise ship though I've never been on one...I was imagining when people board a cruise ship and they wave goodbye on deck... on a cruise ship you can relax and you're not forced to meet certain timelines and due dates." In her journal she also noted that she spent less time focusing on physical sensation in this session, "this session, there was a focus on my emotions more than my physical self."

Elizabeth's exit interview took place four weeks after her last session. In the interview she reflected on the difficulty experienced in session, "It was a little...difficult. I mean through all five of the sessions because I'm used to being up and moving and going and...the only time that I ever really stop and slow down is for bedtime. And so we had a lot of issues where...you know she'd ask me how I felt and I'd say well I'm tired and we had a lot of issues of...my attempting to fall asleep on her...it would be a little jarring to hear my own thoughts repeated to me... it just took a while to get used to it...because everything was so different from what I was expecting." She also noted that she was not looking to gain anything in particular from PRYT, "I was, I was looking at it from purely an inquisitive I don't know almost academic endeavor."

She mentioned valuing the interactive aspects of psychotherapy and that in PRYT she felt more like she was working alone and that this inhibited what she was able to express and explore in session, "I just had an observer that would occasionally reposition me... it wasn't about that conversation [that you have in psychotherapy] it was more about being comfortable with myself and having an observer and working through things that I needed to work through alone... I could work through things alone that would be pretty easy such as stress over the dissertation, you 
know she might give me a couple of prompts about it to pull it out but I would still be the one working through it, whereas working with the counselor I would be looking for him to give me feedback on the issue." She also did not remember most of what was experienced in session, which also may have made using PRYT as a vehicle for change and healing difficult, "unfortunately my journaling is...probably gonna be pretty sparse...there was a lot of times even within an hour of our session I couldn't remember what we did. Or what we were discussing, what we were thinking about, and so I would try really hard to write down what we had focused on or what thoughts had come up but there was a lot of times I just honestly couldn't remember." The one thing she did report taking away from this experience was a greater commitment to mindful living and meditation, “I've been working on um walking meditation... it's made me more mindful not only of what I'm doing or how I'm doing it but what I'm thinking about it because a lot of times I will either overthink something or under-think something and so it's made me try to really be more conscious of that middle road. And most importantly being in the moment because I have a hard time where I live either in the past or the future."

Katie

Katie was a 28 year old, White, heterosexual female who works as a registered nurse. Katie had an autoimmune disease that impacts her daily quality of life. This had led her to seek out alternative and complementary therapies to improve her quality of life because traditional Western medicine has not been able to provide that, "I actually have an autoimmune disease and I guess you could call it research if you will, I do a lot of my own different research to see like what helps me and what doesn't help. Not a huge a fan of the choices that modern medicine has for the issues that I have.” The current treatments she had been using were not working for her as well as she had hoped and she was curious to see if PRYT could be helpful.

The first PRYT session gave Katie a new way to be present with and explore her chronic pain. Through mindfully attending to herself, Katie was able to notice how pain does and does not show up in her body. She also was able to reflect on how much energy she expends each day 
managing her pain, "I feel like I didn't realize how much energy, how much focus, I use to unpain." She actively engaged the session as a way to increase her awareness and find new coping tools, "Just trying to focus on the relaxation... maybe so I can hold onto it...just like so I can know how to manage my emotions away from here," "I feel like I could be in more control if I just let it go...I feel like I hold onto everything, positive, negative, pain...I feel like my body is trying to give me a way to let some of those things go instead of weighing me down."

During the session, Katie noticed that while part of her felt relaxed, another part of her seemed like it was trying to distract her focus away from the relaxation and to instead focus on an area that was still experiencing pain. I invited Katie into a two-part dialogue in which she could let these two opposites parts speak to one another. This dialogue allowed Katie to further explore her pain and ways to improve her quality of life, “I feel like multiple parts are fighting...I feel like the pain I started with is gone, then I got really calm and in a good place, but now I can feel pain in other places. Distraction [the part of her where she experiences the most pain she named Distraction for purposes of the dialogue] has a lot of tools. I feel like I'm trying to let it go and when I let one pain go another shows up...[Hope says(a part of herself that is pain free she named Hope for the purposes of the dialogue)] that I can still be in control. That the Distraction is just that, it's a distraction...I feel like Hope is teaching me...giving me tools to block Distraction...I feel like part of it's awareness that there's a distraction there in the first place." The increased insight and exploration left her feeling empowered, "I can be in control," and created a commitment to try progressive muscle relaxation on her own as a potential coping tool.

Following the session, Katie felt drained from the exploration and took a nap. She woke up feeling physically well and hopeful that future sessions may benefit her, "I slept well for several hours (unusual for me) and then woke up pain free (also unusual for me). After the nap I felt lighter, hopeful even. I am excited to explore these sessions and use them to my benefit in the future." Katie also followed through on her commitment to try a progressive muscle relaxation and noted in her journal that she experienced some pain relief from the relaxation 
exercise. About one week following her first session, Katie's pain began to return. She noted that stretching at home did not improve her pain the way stretching in session does. Katie thought that the practitioner assisted stretching in session was able to support and help her in ways that stretching on her own could not.

Session two was difficult for Katie. Mindfully observing herself in session, she became acutely aware of how pervasive her chronic pain is. She acknowledged that instead of being a part of her, it had come to define her, "I feel like the pain is there so often that I dedicate all my faculties to it and then when it's gone I don't know what to do with myself. I don't know how to be me if I'm not hurting." This realization was painful, "This isn't the person I wanted to be" and served as a wake-up call, "I feel like I realized that I'm in denial...about how the pain effects me and how I let it effect other people." At the end of the session, Katie struggled to find an action step to apply what she learned to her outside life. She acknowledged how stuck she felt and resolved to talk to her husband to get support and try to find a way to improve her day-to-day experience. Katie followed through once again on her action step, as noted in her journal, and she and her husband decided that she would contact a naturopath for further assistance in the management of her autoimmune disease.

In the third session, Katie began to rekindle the hope experienced in her first session. I led Katie in a body scan. She was asked to observe each part of her body including the sensations, emotions, and thoughts that arose from each part. This piece-by-piece exploration heightened her awareness of the way mind and body influence one another, "Noticing physical changes as I lay here. Noticing different sensations, different strengths of sensations in the muscles, noticing how physically (pause) how my physical state ties in with other states." This empowered her to feel like she could have more control over her day-to-day experience, "I feel like (pause) I can choose how I feel physically, feel like I can choose how I feel emotionally, trying to (pause) see how it plays out," and to become curious about the lasting impact of different thoughts and emotions on her body, "wondering what would happen if I relaxed the 
muscles, wondering if this is even where the muscles should be, wondering if tension or worry has caused them to find a home in a different position." She noted in her journal that the exploration in session also challenged what she had previously believed she could tolerate in terms of pain, "I believe this in conjunction with the last session to show me that I would tolerate more than I had come to believe in the last few weeks."

The fourth session increased Katie's awareness of how the experience in session could be applied to outside life, "noticing that between the stretches kind of gives my muscles a break and I was thinking it helps and I can relate it to staying calm... when my muscles [are stretched] and then you get the break I can feel them loosening again. If I give myself a break when I don't feel calm hopefully that won't exasperate any feelings I'm having."

I also observed Katie's pattern of trying to plan for what was coming next and used pose choice to challenge that pattern by doing something unexpected in a pose sequence. Katie again took this opportunity to apply the experience to her outside life, "trying to anticipate what's coming next...sometimes I feel like that's when I lose my cool the most is when the things I expect don't happen or don't happen the way I expect them to. (I move her arm in a different way than I had on the previous side and ask, “what's happening now?") That's not the way I thought we were going to do it...sometimes when I'm hurting it takes a lot of effort to control other aspects of my day so my mood, what I say and do are harder to control because I spend so much energy on pain so I feel like if I know what's coming next I can be ready for it...I can feel a stretch but it feels pretty good, so even if it's not what I expect good things can still come out of it." Katie's experience in session was able to expand her beliefs about herself and the world, "a little afraid if you turn my head the other way it's gonna hurt again too (I ask, "Do you want to explore turning your head the other way?") yeah...(after turning head) Not as bad as I thought it was gonna be. (I invite Katie to open her eyes and see how far head is turned) A little bit impressed that I could make it that far...I think that I'm probably my own worst critic...Knowing things are probably not going to be as bad as I thought they'd be when they don't go as planned." 
In her final session, Katie brought in the awareness gained from previous sessions and continued to expand her knowledge of herself and how she relates to her life situation. She explored the ways she can still have control over herself and her experience even when other aspects are out of her control, "I can really feel a stretch. Depending on how I stand changes where I can feel the stretch... all through the back of my legs and through my back and I can change where I feel that muscle tension based on the position of my knees...makes me feel more in control." She also explored her physical boundaries, choosing when to stay in a pose, "There's an edge of pain (I ask, "an edge you want to stay with?) Yeah...I feel like I am learning my boundaries...another way to know what to expect to stay in control," and when to leave a pose, "I need to move." This left her feeling empowered, "I am in charge of my decisions...I have to take an active role in making decisions that are good for me." In her journal later that day, Katie asserted that she wanted to continue to use the knowledge gained in sessions despite today being her last session. She noted that what she learned from today was another example of how her beliefs do not always match reality, "sometimes pushing the boundaries was more uncomfortable in my head than they actually were for me body."

Katie's exit interview took place six weeks following her last session. She noted several areas that have had a lasting impact on her. Two things that stood out, she reported, were the assisted stretches, "well I think it's affected me in a couple of ways. One, the assisted yoga positions was something that I really enjoyed. And it's something that I have continued to do. So for me part of it is that I can control the positions that I get in and out of and part of it is that I still need someone to help and so that's something that I plan to continue to do for a long time. And hopefully as I go through it and do it more then I'll have some better mobility and flexibility and be able to do some things without assistance. But until then I got something," and increased insight, "Right and then the rest is probably more mental, emotional. Like I said I learned some things about myself that I didn't really know or I was ignoring. And you know emotionally and well both emotionally and mentally I kind of opened some doors. It helps me understand some of 
the coping mechanisms that I choose to have, it helps me to understand what maybe a better choice in a coping mechanism would be. Basically just learning a little more about myself." She also noted the lasting impact that session four has continued to have on her, "Really there's a specific conversation that Jenilee and I had that really stands out. And I mentioned a reference to it earlier and it has to stood out since... I mean since it happened basically, and that was when you know I really didn't expect her to change it up on me and then when she did it wasn't as bad as I thought it was gonna be. And so it, I kind of learned some things about me like I said earlier but then I also kind of learned some ways to put things into play or into practice like maybe I shouldn't be as hesitant, maybe I shouldn't always wade in, sometimes I can jump in and it will be ok. And like I said things will work and things won't work but that specific conversation has really stuck out for me because that's one of the things that I feel like I need to work on personally."

Sally

Sally was a 54 year old, White, heterosexual female who runs a wellness mentoring business. For the past two years, Sally had been taking risks and trying out things that intimidated her. This led her to volunteer for multiple research projects in the recent past, including this study on PRYT. Sally entered into the study out of curiosity more than anything without any particular goal or agenda. Despite her commitment to taking risks, participating in PRYT and the study was very far outside of her comfort zone. Touch was particularly scary for her due to a history of molestation at the hands of her pediatrician as well as physical abuse throughout childhood.

Sally arrived at her first session after attending a grief conference during which she processed her grief over her brother. She was still in the midst of processing through the experience and the first half of her session provided a space to continue that processing. Sally also had fears around touch and felt a sense of safety and connection due to experiencing safe touch, "(Icome hands on for the first time with centering touch and tears show up for Sally, 
practitioner asks, “what's happening now?") Client whispers, 'I miss my brother." Touch remained impactful throughout her session and while in a pose in which the practitioner holds the client (actually called the "mother pose" in PRYT), Sally stated, "Just wish that I had that kind of mother...I wasn't held or touched so, I met a lot of people that their dead sibling was the wrong one that died and that's how I felt too....and that's how my mother felt."

After this point in session the client became much more silent and continued to process internally. At several points she stayed silent when probed. Throughout this session she reflected on family experience and relationships. When she chose to speak again she stated, "I'm glad I was so good to my boys...just being a cycle breaker." PRYT appeared to provide a space for her to process both internally and externally as felt appropriate and safe for her.

In her journal following the session, Sally reflected that the method of PRYT helped her feel at ease with her decision to participate, "I very much liked the "closed eyes" idea- I do that a lot with my yoga practice and feel like it fits with inner work, helps me concentrate and let go and makes the practice more meditative...I feel such peace with the decision to go so far (so very far) outside my comfort zone with yoga therapy." She also shared more about her experience with touch in session, "The heart and back (hands on back fingertips on heart) was so moving that tears fell and fell from my eyes. It's amazing to me that someone can care this much about humans and want to help them in this way. Rather ingenious and such a simple 'laying on of hands' in the truest sense... I said that I wasn't touched or held as a child that I can remember. That is beyond unfair. I think that's why I wept- even though I have a physically loving relationship with my husband and kids now, I still long for and deserved one with my mother." The embodied nature of the work also evoked memories, both pleasant and difficult, "another thing that came up for me was a physical memory of doing a backbend on the balance beam as a little girl... The facedown position was very painful for me- emotionally. I felt like I couldn't protect myself from being beaten with a belt. It caused a pretty severe flashback and shut down my ability to speak about my pain. The belt buckle sound that came from her using a yoga strap 
to lift my legs probably triggered a memory as well. Interesting how my body knows. I'm $\underline{\text { so }}$ safe though. I know that now." Despite the evocation of her trauma memory, Sally ended the session feeling empowered, “I also said I'm a ‘cycle breaker' because I am. I feel very proud of that...I said, 'I'm glad I'm so good to my boys' I truly am.” Sally also experienced some discomfort and censoring of herself in session due to being videotaped, "I really feel inhibited being video taped!"

Sally was much more quiet in her second session, opting at several points to keep her thoughts and feelings to herself. This allowed her to reflect on her relationship with being recorded and to decide how she would like to engage with the work. In her journal after the session she wrote, "I wish I knew what memories my body holds. I feel like I have deep pain that is neatly tucked away and I'd like to take it out and examine it. Repressed memories seem to be something I'm ready and willing to deal with but also scared to deal with too...I know I can handle them and will be so free and happy without them buried. Am I too private to share these inner thoughts with Jenilee and her instructors though? Probably...Maybe what I get out of this opportunity is 7.5 hours of 'me time' and some de-sensitizing on being touched so that I can get a massage someday." Also, despite choosing to process internally, Sally was able to gain insight and make meaning from her experiences in session, "I thought it was cool how being more flexible and open applied to my physical life but also my emotional/spiritual life also."

In her third session, Sally voiced her appreciation for the opportunity provided in session to be present with herself, "It's just been helpful to have this in my life...integrating the yoga and meditation...focusing on me.” This witnessing of herself allowed her to gain clarity, "Just making connections in different parts of my life I guess, listening to a talk on humor versus sarcasm and realizing that's what I'm setting limits on with my brother with regards to grief," and trust in her own process, "The answers always come, just have to wait and not be impatient." It also allowed her to witness how she handles difficult situations. After choosing to endure a physically difficult 
stretch, Sally said, "I feel like a survivor...I am a survivor...I'm a thriver, not a victim." She was able to make meaning from this physical experience and relate it to her life as a whole.

In her journal following this session, Sally reflected on the fact that the client in PRYT is responsible for both the content and the follow-through within and between sessions, "There's no continuity between sessions because it's not the job of the 'therapist' to follow-up or ask questions- but it's weird because I think 'hey did I follow through with that intention from last week?' But it's also a clean slate and refreshing to not 'fail' at something when it wasn't a good fit. Also to not have the stereotypical 'angry therapist' who is going by their notes instead of looking at who you really are." She also reflected on what she gained from session but did not share aloud, 'my 'I' message was 'I am resilient.' Loved that! I chose not to share it aloud- I felt protective of it." Sally embraced the opportunity to learn from herself provided by PRYT, “I'm so grateful to have the opportunity to listen to 'me' (via my physical body)," and to create change in her life, "I'm sitting here...thinking on how much yoga therapy has meant to my personal growth-it has changed me forever in accepting touch and help with unconditional support. But also affirmed my innate belief system to heal from within. I may patiently wait for the answers but they're all coming from me! That's so deep and profound. My own knowing truly is the best fit."

While observing herself in the fourth session, Sally noted several ways she has changed over time, both physically, "that's a pretty big range of motion, I'm pretty surprised," and psychologically, “well if I can get a good recommendation from someone...I might get a deep tissue massage. I don't know, just saying it feels kind of creepy but I might because of this [PRYT], you know, just being willing to go past where I'm afraid," and, "It's just a really big stretch...it's weird because in a former life I would avoid any kind of sensations like this, just kind of avoid any kind of stretch, now it's all I want to do...I just didn't like it because it hurt... because I had used up all of my pain cards and didn't want to be in pain anymore and now I don't consider it pain, it's just good I guess." 
She continued exploring the changes she had made and insights she had gained in her journal, "I still can't believe what I've learned in a short time. How to be with someone and allow therapeutic touch. How to push myself past my comfort zone on so many levels... another thing I gained from this was how much I deserve(d) touch (as a kid and now)... I noticed when I put a hammock in my living room that I couldn't get enough of the gentle rocking/wrapping embrace. I wasn't held or cuddled much. And I have other reasons for touch aversion as well. So this has opened me up to safe, soothing, therapeutic touch. A miracle really. When all of my defenses were saying 'run!!,' I stayed and I'm so glad.” She also emphasized the opportunity that PRYT provides to be present with yourself. Although she kept being distracted by thoughts about a large shipment of corn she had received, she consistently brought her awareness back to the present moment, "I can make tortillas in the dehydrator, or try to be in the NOW at Yoga Therapy," and acknowledged the importance of spending time with herself, "These sessions represent my choice to "pencil myself in" with some down-time. 90 minutes for me."

In session five, Sally continued to spend much of her session in silence. When she did choose to speak it was often to focus on her physical sensations, "It's relaxing, the stretch, not as tight...moved out of the fight or flight response of it being a stretch and moved into letting it happen (I ask tell me more, client is silent)." She also remained silent throughout the closing meditation. PRYT allows the client to choose how much is shared with the practitioner and Sally embraced this permission to choose.

Sally's journal highlights how her fifth session contrasts with her first. Where she had a flashback triggered in the initial session that shut her down for a while, she was instead able to move through a similar flashback in this session with ease, "I remembered another move Jenilee did- she put a block between my knees with a belt tied around them then another belt to pull traction on my upper back ...I cringed a bit at the noise of the belt buckles (childhood flashback) but ended up forgetting about it right away and was able to enjoy the stretch immensely." 
Following the conclusion of her sessions, Sally reflected on what they meant to her, "I've been missing my meetings...for Yoga Therapy- it was a transformational experience...the way it reaches inside you in such a unique way. I can see so many benefits. I'm open (now) to seeking massage therapy when before the trust just wasn't there- and I feel like I tried something new and outside my comfort zone," and how they supported her growth despite her inhibition due to being taped, "I know that in 'real life' I would have shared more if we weren't filming- and I definitely was able to get in touch with deep emotions and release some buried issues/feelings to a degree in sessions and very much at home with my own family here to talk to as well as within my journal."

Sally's exit interview took place three weeks following her last session. In the interview she reflected on the therapist's presence as a big factor that helped her to continue to come despite discomfort, "What led me to not quit maybe or not you know after we had our first discussion about it, was probably just how Jenilee is, she's a very welcoming and unconditional person, and very calming." She also reflected on what the therapist did to help her feel safe with being touched in session, "the thought of anyone touching me is like creepy and uncomfortable and awful. And so that was something that she was very mindful of because we talked about it beforehand and she would tell me where she was in the room 'I'm moving over here, I'm going to put my hand here."' She noted that the sessions helped her prioritize checking in with herself, “And so I was just insanely busy and so it helped me slow down because when you first check-in you literally check-in with what are you feeling and what are you thinking? And I realized that I could do that anywhere." She also appreciated the meditative quality of the sessions, "you keep your eyes closed the whole time and so um the focus is just in. In the now. And that's something you're hardly ever doing in your life."

Lastly, she discussed the memories that surfaced during the work. She noted that she thinks that exploring her memories more would have been beneficial. She would have been open to exploring them had she not been being recorded, "Well I would say one of the key things for 
me was that you like I had a memory of effortlessly doing a backbend on the balance beam as a child and then my legs flicking over and stuff and when I'm in like a bent over the ball pose I had, you're not, I don't believe your body stores things 'cause that's kind of like biologically not true but your mind has memories that are associated with positional qualities of your body and so like when she had the yoga belt buckles she clinked around you know, I've been beaten with a belt many many many many times and that was like gheeee really nerve wracking and so I had to fight to not just open my eyes and say wait what are you doing put that down. And I had to remember that it was her and I had to remember where I was and that I was safe and that I'm 54 years old and I can you know fight for myself and those types of things. But I think that's why it's helpful. So if I could explore that more that would be where like I would go into those memories or I would go into maybe other types of memories that come up, good and bad." 


\section{CHAPTER IV}

\section{DISCUSSION}

This study was designed to gain understanding of the experiences of clients who receive individual PRYT sessions. Session videos, journals, and phenomenological interviews for four participants were analyzed using phenomenological thematic analysis (Van Manen, 2014) and demographic information was gathered from initial intake paperwork. Data analysis elicited seven phenomenological themes and phenomenological case studies for each participant.

Several steps were taken to ensure the trustworthiness of the data and results. A certified PRYT practitioner independently examined sessions for authenticity. Also, data results were reviewed by an internal and an external auditor as well as verified by participants.

Participants were four White, heterosexual, cis-gendered females living in Stillwater, Oklahoma. Each had an individualized reason for being interested in the study. Two hoped that PRYT may help them with specific issues in their lives, one was interested in trying something new, and one was simply curious about PRYT. Per their report, all felt that their initial intentions were met. 
Amber, who hoped PRYT might help with anxiety, felt that the sessions increased her understanding of the role anxiety played in her life and helped decrease her anxiety symptoms. Katie, who was looking for something to help with her chronic pain, believed that the sessions gave her more insight into how she was currently coping and provided new coping skills to explore. Sally, who volunteered in order to try something outside of her comfort zone, stated that PRYT changed her relationship with touch and reaffirmed her belief in her ability to find healing from within. Elizabeth, who was interested to find out more about PRYT, was surprised by the meditative nature of the work and struggled with staying present for 90 minutes but reported that she has now incorporated more mindfulness into her life as a result of the sessions.

The first research question was: what are the clients' experiences of the phenomenon of PRYT? The participants in this study expressed themes of mindfulness, self-awareness, mind/body connection, in-vivo experience of new behaviors, client direction of sessions, and empowerment as the essence of the experience of PRYT sessions. Mindfulness was both encapsulated in the practitioner's verbal interventions as well as the participants observing present moment thoughts and sensations throughout the duration of sessions. Mindful observation in session often appeared to lead to new insights and awareness about their cognitions, emotions, and behaviors.

The body serves as a primary intervention tool throughout the sessions with clients observing breath and physical sensation as well as being invited to experience different postures and movements during the sessions. Each participant noted greater insight into mind/body connection. They noticed the effect of cognition and emotion on the body, observed how the body can be used to improve coping through movement and breathing, and experienced different thoughts and emotions associated with different areas of their bodies.

Participants were able to experiment with new behaviors in session. This was particularly salient for Katie and Amber who both observed ways that their expectations and 
reality were incongruent. They experimented with physical movements that provoked fear and both noted that the movements were not as threatening as they had previously believed.

In PRYT, clients are informed from the beginning that they can self-direct movement in session and can choose when and how to speak. They are also told that the practitioner's verbal inquiries in session are invitations that they can choose to accept or decline (Phoenix Rising Yoga Therapy, Inc., 2008). Each of the participants exhibited this self-direction through silence, choosing to stay in or leave a pose, or by indicating they no longer wished to discuss certain material. For Katie, this provided the opportunity to choose to stay with challenging material while for Elizabeth it created the chance to disengage from emotionally enhanced stimuli. Sally frequently chose to remain silent in session but then expressed much in her journal after.

Lastly, the clients shared many empowering statements throughout the sessions.

Oftentimes this occurred in the I-statement created in the final meditation but it was also present throughout as clients expressed new hope for change and a belief in their ability to create this change.

The second research question was: how does receiving PRYT sessions impact the clients' lives? Life changes emerged as its own theme through the course of data analysis. At the end of each PRYT session, the participants were asked to identify an action step related to what they noticed in the session that day. On several occasions, participants chose steps that had the potential to directly support change. For example, at the end of one session Katie resolved to discuss with her husband changes that could be made to help support her in managing her chronic pain and auto-immune disorder. Amber also highlighted in both her journal and subsequent sessions the impact that sessions were having on her ability to manage her anxiety.

In the exit interview, each of the participants noted changes they attributed to receiving PRYT sessions. Amber stated that she now exercises more and feels less anxious in general. Katie noted that she has incorporated assisted stretching into her coping regimen and that she has been exploring ways to be more comfortable when she is not in control in her life. Elizabeth 
stated she is able to be more mindful in her day-to-day life and Sally reported that she felt forever changed by allowing herself to receive therapeutic touch.

The perceived effectiveness of PRYT varied greatly between clients with Amber reporting very significant changes in her anxiety and Elizabeth reporting few overall changes. Elizabeth was the least comfortable with the format of the sessions and she was the least likely to stay with and explore distressing material. This may serve as an example that one approach of any modality will not be effective for all clients. PRYT may be a better fit for clients who are more comfortable with self-direction and self-reflection.

Touch, which was present in every PRYT session analyzed, has been a controversial subject since psychotherapy's inception. Psychologists struggle to constructively discuss the use of touch and often are remiss to explore the use of touch in psychotherapy (Westland, 2011). However, in Sally's case, touch was the primary vehicle for healing.

Arguments against touch that therapists cite include: fear clients will respond negatively, potential disruption of a client's process, using touch to quell therapist's own anxiety, and boundary crossing that may lead to violation (Heatherington, 1998; Strozier, Krizek, \& Sale, 2003). Perhaps because there is limited if any training on how to use touch in psychotherapy and therapists often do not know how to engage clients in discussion on the use of touch (McNeilHaber 2004; Stenzel \& Rupert, 2004; Strozier et al., 2003) there is greater risk for the previously cited concerns. The ethical use of touch including informed consent of its use was a focal point of my PRYT training. Despite this, I am hesitant to use touch within my psychotherapy practice due to limited training on its use within both my Master's and Doctoral training programs. It remains unclear to me how to broach the topic of touch with psychotherapy clients and how to implement a touched based intervention.

In my sessions with Sally I was acutely aware of her trauma history and strove to provide touch in a way that would feel safe for her while also providing the opportunity for her to decline touch. Per her report, the way touch was used in her sessions was incredibly healing both in 
terms of providing insight into her relationship with her mother and also by creating an opportunity to have a positive experience receiving therapeutic touch. Conceivably touch could have a similarly healing effect within psychotherapy if there was competency in and consent of its use.

Periodically, touch arises as a topic in various psychology related conferences and quite often the dialogue becomes an argument from two equally vehement groups: those that believe touch has no place in psychotherapy and those that believe touch is an important part of the therapeutic process. This inability to constructively talk about and explore the use of touch in psychotherapy is yet another component that cripples the ability of the field to truly explore this phenomenon and what usefulness it may have (Westland, 2011). Furthermore, some therapists that do use touch are aware of the stigma around its use and are remiss to discuss it. Sometimes they even express shame that another colleague may see them engage in touch with a client (Harrison et al., 2012). It would seem that many of the beliefs about the appropriate role of touch in psychotherapy stem from personal beliefs and biases. It is time for the field of psychology to more thoroughly research this topic. Only through systematic investigation will we be able to use evidenced-based knowledge to inform training on and implementation of touch based interventions, if appropriate.

Many PRYT practitioners do not have a background in mental health. PRYT is also nonprescriptive and does not offer diagnosis. However, it relies heavily on insight-oriented practice to facilitate life change with the body as the primary vehicle for both insight and healing (Phoenix Rising Yoga Therapy, Inc., 2014). Despite the differentiation between PRYT and psychotherapy, elements of the PRYT sessions bore similarities to psychotherapy interventions from a variety of theoretical orientations.

Lee, the founder of PRYT, was influenced by the work of Rogers and instilled PRYT with its non-directive nature, the use of unconditional positive regard, and the belief that clients are the experts on their lives (Lee, 1995). The two-part dialogue intervention highlighted in 
Katie's case study in which she a conversation between "Distraction" and "Hope" can be compared to both Narrative and Gestalt interventions. The process of viewing separate parts of self in order to increase understanding and reintegrate into the whole aligns closely with the Gestalt principle of holism (Corey, 2005). It can also be understood through the lens of externalization in Narrative therapy (Corey, 2005). In the two-part dialogue, Katie externalized the problem of her chronic pain and used the other externalized "Hope" to help re-author her personal narrative. The emphasis on the now in PRYT is directly comparable to Gestalt therapy's prioritization of the present moment as well (Corey, 2005). Clinicians who work from insightoriented, non-directive, and collaborative theoretical orientations might find resonance between their work and the work done in PRYT sessions.

The PRYT Training Institute now offers a mental health practitioner track for mental health professionals who wish to integrate PRYT into their clinical practice (PRYT Training for Mental Health Professionals, 2014). There were several times during the sessions where I saw opportunities for other interventions if I had been conducting the sessions as a counselor. For example, with Elizabeth I think it would have been helpful to highlight the pattern I observed of her moving away from distressing material and to also offer psychoeducation on the potential benefits of exploring this same material. As Elizabeth noted in her exit interview, she values the feedback given in psychotherapy and missed that in PRYT. I think in her case, she would have benefitted more from an integration of PRYT and psychotherapy than she did from PRYT alone. It may be that in general, for clients who tend to avoid distressing stimuli and who may be less self-directive towards change are not best suited to a purely PRYT approach.

In my work with Amber, I referred her for counseling after the session where she was struggling with her ulcer. She reported in her interview that PRYT improved her anxiety. However, offering coping tools to help her manage her anxiety may have helped her with symptom remission while she continued to address her anxiety in PRYT. Although I am a person-centered counselor, I have found in my own practice that offering education and using 
directive interventions sometimes helps clients move past obstacles that inhibit their ability to connect with their own innate valuing process. It would be interesting to see if I, and other mental health practitioners, who are integrating PRYT into their practice find it to be beneficial to utilize directive and educational interventions alongside PRYT techniques.

\section{Limitations}

The results of this study are not intended to be generalizable. Although these four participants reported increased mindfulness and other life changes, it cannot be assumed that this is typical of all persons who receive PRYT. Additionally, although the authenticity of the method was independently verified, it cannot be assumed that other PRYT practitioners would have identical sessions. Although the basic format should be similar between practitioners, there is still choice about when and how to use verbal interventions and body postures. This study, as with all phenomenological studies, is also not replicable. It is assumed that the lived experience of one group will not match the lived experience of another even if they were to experience the same event (Van Manen, 2014). Additionally, the sample size was small and all participants were White, heterosexual, cis-gendered females.

The participants were aware that I would be reading their journals and hearing their interviews. Due to the fact that I also provided their sessions, they may have censored themselves at times because of our dual relationship. The dual relationship as practitioner and researcher may have led participants to want to appear favorably and/or to protect my feelings. It is also possible that this dual relationship could have led to reticence to express discrepancy if there were any findings that the participants disagreed with.

\section{Implications}

This study provides insight into the experience of PRYT as received by these four participants and offers potential directions for future research. The positive benefits of mindfulness are well known (e.g. Carmondy \& Baer, 2008; Keune \& Forintos, 2010; Prazak, Critelli, Martin, Miranda, Purdum, \& Powers, 2012) and PRYT may provide another avenue that 
clients can use to enhance their mindfulness skills. It would be interesting to explore changes in mindfulness as well as possibly compare PRYT to other mindfulness-based interventions.

The concept of embodiment, the belief that all of life including thought and feeling is experienced through the body, is a topic that has plagued philosophers such as Husserl and Merleau-Ponty (Carman, 1999). It is also now a topic of debate in psychological sciences through the lens of embodied cognition (e.g. Claxton, 2012; Leitan \& Chaffey, 2014). As our understanding of how the body impacts psychological processes grows, mind/body approaches such as PRYT may provide tools that can be incorporated into psychological practice to more holistically treat clients.

Katie, it could be argued, changed her relationship with her body by gaining insight into what she could tolerate, increasing her knowledge of how her physical pain impacted her, and changing how she related to the pain. It has been theorized that experiencing chronic pain alienates oneself from her/his own body (Svenaeus, 2015). It would be beneficial to explore how PRYT and other mind/body approaches affect chronic pain clients.

PRYT and other embodied approaches to therapy may also provide a unique avenue for social justice on an individual level. Those with marginalized bodies, such as women and the differently-abled, are often the subject of objectifying and disembodying actions and remarks. Also, those who experience embodied knowing (e.g. mothers who choose to birth at home out of trust of their body) are routinely disenfranchised in the scientific community (Clough, 2013). For the women in this study, PRYT provided an avenue to experience embodiment and explore their body's knowing. Perhaps it could be a viable avenue to honor both embodied knowing and marginalized bodies.

In my opinion, by using dialogue alone in counseling, we miss out on reaching the full range of human experience. However, my psychotherapy training also has not adequately addressed the use of the body in session. PRYT training provides a unique skill set that may be beneficial in counseling. Certainly in the case of Katie, a mind/body approach fit in with her 
intentions. It would be interesting to compare treatment outcomes between PRYT and traditional therapy for similar presenting concerns. Per her report, PRYT also helped Amber better understand the impact of her anxiety on her body. In the case of clients with anxiety, it might be beneficial to compare outcomes between traditional therapy, PRYT, and an approach that integrates PRYT and psychotherapy interventions.

Further research is needed to expand upon the current findings and understand the effectiveness of PRYT for a broader range of individuals. Controlled trials with large sample sizes would help us better understand the overall usefulness of PRYT and what populations it may be most effective for. This study also points to the potential use of touch in psychotherapy. The case study of Sally could be used as an illustration to help dispel some of the fears surrounding touch in order to allow psychologists to effectively discuss and explore touch as an intervention. Lastly, the case studies provide examples of how body-based interventions may increase insight and create unique opportunities for behavior change. Future research on using the body in psychotherapeutic practice could help clarify the effectiveness of these types of interventions to support therapeutic goals. 


\section{REFERENCES}

Arambula, P., Peper, E., Kawakami, M., \& Gibney, K. H. (2001). The physiological correlates of kundalini yoga mediation: a study of a yoga master. Applied Psychophysiology and Biofeedback, 26, 147-153.

Bilderbeck, A. C., Farias, M., Brazil, I. A., Jakobowitz, S., \& Wikholm, C. (2013).

Participation in a 10-week course of yoga improves behavioural control and decreases psychological distress in a prison population. Journal of Psychiatric Research. doi:

10.1016/j.jpsychires.2013.06.014

Boccia, M., Piccardi, L., \& Guariglia, P. (2015). The meditative mind: A comprehensive metaanalysis of MRI studies. BioMed Research International, 2015, Article ID 419808, 11 pages. doi: $10.1155 / 2015 / 419808$

Booth-LaForce, C., Thurston, R. C., \& Taylor, M. R. (2007). A pilot study of a hatha yoga treatment for menopausal symptoms. The European Menopausal Journal, 57, 286-295.

Brown, R. P., \& Gerbarg, P. L. (2005a). Sudarshan kriya yogic breathing in the treatment of stress, anxiety, and depression: part I- neurophysiologic model. The Journal of Alternative and Complementary Medicine, 11, 189-201. 
Brown, R. P., Gerbarg, P. L., \& Muench, F. (2013). Breathing practices for treatment of psychiatric and stress-related medical conditions. Psychiatric Clinics of North America, 36(1), 121-140. doi: 10.1016/j.psc.2013.01.001.

Carlson, L. E., Speca, M., Patel, K. D., \& Goodney, E. (2003). Mindfulness-based stress reduction in relation to quality of life, mood, symptoms of stress, and immune parameters in breast and prostate cancer outpatients. Psychosomatic Medicine, 65, 571-581.

Carman, T. (1999). The body in 53epress and merleau-ponty. Philosophical Topics, 27, 205-226.

Carmondy, J., \& Baer, R. A. (2008). Relationships between mindfulness practice and levels of mindfulness, medical and psychological symptoms and well-being in a mindfulnessbased stress reduction program. Journal of Behavioral Medicine, 31, 23-33. doi: $10.1007 / \mathrm{s} 10865-007-9130-7$

Claxton, G. (2012). Turning thinking on its head: How bodies make up their minds. Thinking Skills and Creativity, 7(2), 78-84. doi: 10.1016/j.tsc.2012.03.004

Clough, S. (2013). Pragmatism and embodiment as resources for feminist interventions in science. Contemporary Pragmatism, 10, 121-134.

Cooper, C., Balamurali, T. B. S., Selwood, A., \& Livingston, G. (2007). A systematic review of intervention studies about anxiety in caregivers of people with dementia. International Journal of Geriatric Psychiatry, 22, 181-188.

Coster, G. (1972). Yoga and Western Psychology. New York: Harper \& Row.

Creswell, J. W. (2013). Qualitative Inquiry and Research Design: Choosing Among Five Approaches. ( $3^{\text {rd }}$ Ed.) Thousand Oaks, CA: Sage Publications, Inc.

Culos-Reed, S. N., Carlson, L. E., Daroux, L. M., \& Hately-Aldous, S. (2006). A pilot study of yoga for breast cancer survivors: physical and psychological benefits. PsychoOncology, 15, 891-897. doi: 10.1002/pon.1021

D’Mello, S., Dale, R., Graesser, A. (2012) Disequilibrium in the mind, disharmony in the body. Cognition and Emotion, 26(2), 362-374. doi: 10.1080/02699932.2011.575767 
Desikachar, T. K. V. (1995). The Heart of Yoga: Developing a Personal Practice. Rochester, VT: Inner Traditions International.

Dolbier, C. L., Rush, T. E. (2012). Efficacy of abbreviated progressive muscle relaxation in a high-stress college sample. International Journal of Stress Management, 19(1), 48-68. doi: 10.1037/a0027326

Dorjee, D. (2010). Kinds and dimensions of mindfulness: Why it is important to distinguish t them. Mindfulness, 1, 152-160.

Feuerstein, G. (1998). The Yoga Tradition: Its History, Literature, Philosophy and Practice. Prescott, AZ: Hohm Press.

Flack, W. F., Jr. (2006). Peripheral feedback effects of facial expressions, bodily postures, and vocal expressions on emotional feelings. Cognition and Emotion, 20(2), 177-195. doi: 10.1080/02699930500359617

Forstmann, M., Burgmer, P., \& Mussweiler, T. (2012). "The mind is willing, but the flesh is weak": The effects of mind-body dualism on health behavior. Psychological Science, 23(10), 1239-1245. doi: 10.1177/0956797612442392

Froeliger, B. E., Garland, E. L., Modlin, L. A., \& McClernon, F. J. (2012).

Neurocognitive correlates of the effects of yoga meditation practice on emotion and cognition: A pilot study. Frontiers in Integrative Neuroscience, 6. doi: 10.3389/fnint.2012.00048

Gard, T., Taquet, M., Dixit, R., Holzel, B. K., de Montjoye, Y. A., Brach, N., . . Lazar, S. W. (2014). Fluid intelligence and brain functional organization in aging yoga and meditation practitioners. Frontiers in Aging Neuroscience, 6, 76. doi: 10.3389/fnagi.2014.00076

Glesne, C. (2011). Becoming Qualitative Researchers: An Introduction. (4 ${ }^{\text {th }}$ Ed.) Boston: Pearson Education, Inc.

Goldin-Meadow, S., Cook, S. W., \& Mitchell, Z. A. (2009). Gesturing gives children new 
ideas about math. Psychological Science, 20(3), 267-272. doi: 10.1111/j.14679280.2009.02297.x

Grilley, P. (2002). Yin Yoga. Ashland, OR: White Cloud Press.

Häfner, M. (2013). When body and mind are talking: Interoception moderates embodied cognition. Experimental Psychology, 60(4), 255-259. doi: 10.1027/1618$3169 / \mathrm{a} 000194$

Heatherington, A. (1998). The use and abuse of touch in therapy. Counseling Psychology Quarterly, 11, 361-365. doi: 0951-5070/98/040361-04

Hoffman, S. G., Sawyer, A. T., Witt, A. A., \& Oh, D. (2010). The effect of mindfulness-based therapy on anxiety and depression: A meta-analytic review. Journal of Consulting and Clinical Psychology, 78, 169-183.

Huang, L., Galinsky, A. D., Gruenfeld, D. H., \& Guillory, L. E. (2011). Powerful postures versus powerful roles: Which is the proximate correlate of thought and behavior? Psychological Science, 22(1), 95-102. doi: 10.1177/0956797610391912

Jensen, P. S., \& Kenny, D. T. (2004). The effects of yoga on the attention and behavior of boys with attention deficit/ hyperactivity disorder. Journal of Attention Disorders, 7, 205-216. doi: $10.1177 / 108705470400700403$

Kabat-Zinn, J. (1990). Full Catastrophe of Living: Using the Wisdom of Your Body and Mind to Face Stress, Pain, and Illness. New York: Delacorte Press.

Kinser, P. A., Bourguignon, C., Whaley, D., Hauenstein, E., \& Taylor, A. G. (2013). Feasibility, acceptability, and effects of gentle hatha yoga for women with major depression: Findings from a randomized controlled mixed-methods study. Archives of Psychiatric Nursing. doi: 10.1016/j.apnu.2013.01.003

Kokinakis, C. L. (1995). Teaching professional standards: Training yoga therapists in loving presence (Doctoral dissertation). Michigan State Univeristy, East Lansing, MI.

Kraftsow, G. (2002). Yoga for Transformation: Ancient Teachings and Holistic Practices for 55 
Healing Body, Mind, and Heart. New York: Penguin Compass.

Kuttner, L., Chambers, C. T., Hardial, J., Israel, D. M., Jacobson, K., Evans, K. (2006). A randomized trial of yoga for adolescents with irritable bowel syndrome. Pain Research and Management, 11, 217-223.

Lasater, J. H. (2011). Relax and renew: Restful yoga for stressful times $\left(2^{\text {nd }}\right.$ ed). Berkelely, CA: Rodmell Press.

Lalande, L., Bambling, M., King, R., \& Lowe, R. (2012). Breathwork: An additional treatment option for depression and anxiety? Journal of Contemporary Psychotherapy, 42(2), 113-119. doi: 10.1007/s10879-011-9180-6

Langmuir, J. I., Kirsh, S. G., Classen, C. C. (2012). A pilot study of body-oriented group Psychotherapy: Adapting sensorimotor psychotherapy for the group treatment of trauma. Psychological Trauma: Theory, Research, Practice, and Policy, 4(2), 214-220. doi: $10.1037 / \mathrm{a} 0025588$

Lee, M. (1997). Phoneix Rising Yoga Therapy: A Bridge from Body to Soul. Deerfield Beach, FL: Health Communications, Inc.

Leitan, N. D., Chaffey, L. (2014). Embodied cognition and its applications: A brief review. Sensoria: A Journal of Mind, Brain, and Culture, 10, 3-10.

Levine, M. (2000) The Positive Psychology of Buddhism and Yoga: Paths to a Mature Happiness. New York, NY: Psychology Press.

Levitan, A. A., \& Johnson, J. M. (1986). The role of touch in healing and hypnotherapy. American Journal of Clinical Hypnosis, 28(4), 218-223. doi: $10.1080 / 00029157.1986 .10402657$

Levy Berg, A., Sandahl, C., \& Bullington, J. (2010). Patients' perspective of change processes in affect-focused body psychotherapy for generalised anxiety disorder. Body, Movement and Dance in Psychotherapy, 5(2), 151-169. doi: 10.1080/17432979.2010.494853

Levy Berg, A., Sandell, R., \& Sandahl, C. (2009). Affect-focused body psychotherapy in 
patients with generalized anxiety disorder: Evaluation of an integrative method. Journal of Psychotherapy Integration, 19(1), 67-85. doi: 10.1037/a0015324

McNeil-Haber, F. M. (2004). Ethical considerations in the use of nonerotic touch in psychotherapy with children. Ethics and Behavior, 14, 123-140. doi: $10.1207 /$ s15327019eb1402_3

Martin, K. M. (2010). The role of yoga as a therapeutic tool and practice for improving cogntivie, emotional, and spiritual wellbeing: A pilot study (Doctoral dissertation). Adler School of Professional Psychology, Chicago, IL.

Mehling, W. E., Wrubel, J., Daubenmier, J. J., Price, C. J., Kerr, C. E., Silow, T.,... Stewart, A. L. (2011). Body Awareness: A phenomenological inquiry into the common ground of mind-body therapies. Philosophy, Ethics, and Humanities in Medicine, 6, 6. doi: 10.1186/1747-5341-6-6

Mishra, R.S. (1972). The Textbook of Yoga Psychology. London: The Lyebird Press Ltd.

Moodley, R., Sutherland, P., \& Oulanova, O. (2008). Traditional healing, the body and mind in psychotherapy. Counselling Psychology Quarterly, 21(2), 153-165.

Moustakas, C. (1994). Phenomenological Research Methods. Thousand Oaks, CA: Sage Publications, Inc.

Netz, Y., \& Lidor, R. (2003). Mood alterations in mindful versus aerobic exercise modes. The Journal of Psychology, 137, 405-419.

Patanjali (trans. 2002 by Stiles, M.) Yoga Sutras of Patanjali. San Francisco: Red Wheel/Weiser, LLC.

Phoenix Rising Yoga Therapy, Inc. (2008). Phoenix Rising Yoga Therapy Certification Training Manual. Bristol VT: Phoenix Rising Yoga Therapy, Inc.

Phoenix Rising Yoga Therapy, Inc. (2014). FAQS. Retrieved from: http://pryt.com/faq/?menu=about

Phoenix Rising Yoga Therapy, Inc. (2014). Why PRYT. Retrieved from: http://pryt.com/about- 
pryt/why-pryt/

Prazak, M., Critelli, J., Martin, L., Miranda, V., Purdum, M., \& Powers, C. (2012). Mindfulness and its role in physical and psychological health. Applied Psychology: Health and Wellbeing, 4, 91-105. doi: 10.1111/j.1758-0854.2011.01063.x

Purohit, M. P., Wells, R. E., Zafonte, R. D., Davis, R. B., \& Russell, S. P. (2013). Neuropsychiatric symptoms and the use of complementary and alternative medicine. Journal of Clinical Psychiatry, 74, 520-526. doi: 10.1016/j.pmrj.2012.06.012

Rohricht, F., Papadopoulos, N., \& Priebe, S. (2013). An exploratory randomized controlled trial of body psychotherapy for patients with chronic depression. Journal of Affective Disorders, 151(1), 85-91. doi: 10.1016/j.jad.2013.05.056

Serpa, J. G., Taylor, S. L., \$ Tillisch, K. (2014). Mindfulness-based stress reduction (MBSR) reduces anxiety, depression, and suicidal ideation in veterans. Medical Care, 52, 19-24. doi: 10.1097/MLR.0000000000000202

Shannahoff-Khalsa, D. S. (2003). Kundalini yoga meditation techniques for the treatment of obsessive-compulsive and OC spectrum disorders. Brief Treatment and Crisis Intervention, 3, 369-382.

Soth, M. (2005). Body psychotherapy today: An integral-relational approach. Therapy Today, 16, 8-12.

Stenzel, C. L., \& Rupert, P. A. (2004). Psychologists's use of touch in individual psychotherapy. Psychotherapy: Theory, Research, Practice, Training, 41(3), 332-345. doi: 10.1037/0033-3204.41.3.332

Stiles, Mukunda (2002). Structural Yoga Therapy: Adapting to the Individual. New Delhi, India: Goodwill Publishing House.

Streeter, C. C., Whitfield, T. H., Owen, L., Rein, T., Karri, S. K., Yakhkind, A., . . Jensen, J. E. (2010). Effects of yoga versus walking on mood, anxiety, and brain GABA levels: A randomized controlled MRS study. Journal of Alternative and Complementary Medicine, 
16(11), 1145-1152. doi:10.1089/acm.2010.0007

Strozier, A. L., Krizek, C., \& Sale, K. (2003). Touch: Its use in psychotherapy. Journal of Social Work Practice, 17, 49-62. doi: 10.1080/0265053032000071457

Svenaeus, F. (2015). The phenomenology of chronic pain: Embodiment and alienation. Cont Philos Rev, 48, 107-122. doi: 10.1007/s11007-015-9325-5

Tracy, S. J. (2010). Qualitative quality: Eight “big-tent” criteria for excellent qualitative research. Qualitative Inquiry, 16(10), 837-851. doi: 10.1177/1077800410383121

Van Manen, M. (2014). Phenomenology of Practice: Meaning Giving Methods in Phenomenological Research and Writing. Walnut Creek, CA: Left Coast Press, Inc.

Waelde, L. C., Thompson, L., \& Gallagher-Thompson, D. (2004). A pilot study of a yoga and meditation intervention for dementia caregiver stress. Journal of Clinical Psychology, 60, 677-687.

West, J., Otte, C., Geher, K., Johnson, J., \& Mohr, D. C. (2004). Effects of hatha yoga and expressive dance on perceived stress, affect, and salivary cortisol. The Society of Behavioral Medicine, 28, 114-118.

Westland, G. (2011). Physical touch in psychotherapy: Why are we not touching more? Dance, Movement, and Body Psychotherapy, 6(1), 17-29. doi: 10.1080/17432979.2010.50859 


\section{APPENDICES}

Appendix A: Extended Literature Review

\section{Mind/Body Connection}

Embodied cognition is the theory that the body and its experiences of the environment directly influence cognition (Leitan \& Chaffey, 2014). Flack (2006) discovered that in a sample of undergraduates, facial expression and body posture significantly influenced emotional experience. 52 undergraduates were asked to adopt certain facial expressions, body postures, and to read a list of words in different ways. A noninvasive fingertip electrode measured each participant's physiological responses and participants were asked to indicate their emotional feelings after each exercise. Multivariate Analysis of Variance with Greenhouse-Geisser corrections revealed that facial expression and body posture significantly affected emotional experience whereas vocal tone did not. Similarly, Huang, Galinsky, Gruenfeld, and Guillory (2011) found that assuming a powerful posture increased confidence more than being given a powerful role in a social situation. Häfner (2013) likewise found that in a sample of undergraduates in the Netherlands, physical body experience influenced decision-making in persons with higher body awareness. 60 undergraduates completed the Body Consciousness Questionnaire (Miller, Murphy, \& Buss, 1981) and were then given a clipboard of varying 
weight and were asked to indicate how many euros they would need to buy different foreign currencies. A General Linear Model showed that persons with higher body consciousness would increase their euro predictions as the clipboard weight increased; there was no correlation found in persons with low body consciousness. In the second experiment, 30 undergraduates were asked to rate a person's harshness while sitting in either a hard or soft chair. These participants' body consciousness was measured through asking them to indicate their heart rate and seeing if those indications matched heart rate readings gained through an electrode. Again, those with greater body consciousness showed that their cognitions are affected by body experience: a softer chair led to a "softer" rating and vice versa. Additionally, bodily movements have been strongly correlated with affective states and have been found to fluctuate based on levels of cognitive distress and frustration (D’Mello, Dale, \& Graesser, 2012). Location specific populations limit each of these studies. However, taken together they show that the body can indeed influence how a person thinks and feels. Despite the growing support for a mind/body connection, in the psychotherapy world, quite often we remain a treatment of "talking heads" (Moodley, Sutherland, \& Oulanova, 2008).

This deficit has led a growing number of people to seek out complementary and traditional healing practices (Moodley et al., 2008; Purohit, Wells, \& Zafonte et al., 2013). Purohit et al. (2013) examined data from the 2007 National Health Interview Survey. They found that persons with neuropsychiatric symptoms, for example symptoms commonly experienced with post-traumatic stress disorder and other psychological complaints, were more likely to seek out complementary mind-body treatments than those without symptoms. Also, the likelihood of seeking complementary treatment was positively correlated with the number of neuropsychiatric symptoms experienced. The reason most commonly cited by participants for seeking complementary treatment was that conventional treatments were not working. Participants reported that they typically did not discuss their alternative treatments with other providers as 
well. The sample was representative of the US population. Women and persons between the ages of 25-64 were the most likely to seek mind-body therapies. Comparably, Mehling, et al. (2011) found in their qualitative analysis of mind/body therapies (e.g. yoga, tai chi, and body psychotherapy) that clients typically reported that they sought out mind/body therapy for specific concerns that traditional treatments had not been able to improve. The participants interviewed reported several benefits from the therapies such as: a greater tolerance of negative emotional states and experience as a result of the therapy, improved awareness of body sensations, improved self-regulation, and integration of mind-body awareness into life context.

Psychology is not the only field to begin recognizing the role that body experience may have in cognitive and emotional experience. The education field has started studying the phenomenon of embodied cognition and has begun to discuss changing the way children are taught in school (Claxton 2012; Goldin-Meadow, Cook, \& Mitchell, 2009). Research has found that children are better able to retain learned math information when learning is paired with gesturing versus not gesturing. Children in third and fourth grades who solved no math problems correctly in a pre-test were randomly assigned into a correct gesture group, a partially-correct gesture group, and a no gesture group. The correct gesture group pointed with two fingers on the same hand to grouped variables and with the index finger of one hand to non-grouped variables. The partially-correct gesture group used the same hand and finger position but pointed to two non-grouped variables with two fingers on the same hand. The correct gesture group answered significantly more problems correctly than the partially correct group, and the partially correct group answered significantly more correctly than the no gesture group. Furthermore, the children in the different groups discussed how they solved the problems in qualitatively different ways indicating that the method of gesturing influenced how the children thought about the math problems as well (Goldin-Meadow, et al., 2009). Claxton (2012), in light of the embodied cognition literature, has stated "Seen from the perspective of contemporary cognitive science, and 
the discipline of embodied cognition in particular, much of education now looks partial, dysfunctional, and anachronistic, predicated on a model of the mind that is well past its sell-by date" (p. 83). He urges the school system to expand its view of intelligence to include the body in education given the body's potential to influence thought and learning. However, similarly to the psychotherapy field, this shift has been slow.

The transition from viewing the body and mind as separate to recognizing mind/body connection has been an arduous process in the Western world (Claxton, 2012; Levitan \& Johnson, 1986; Soth, 2005). Reasons for this may be found in the religious history of our culture with Mosaic Law and Christian beliefs in a metaphysical separation between the body and the mind and soul (Levitan \& Johnson, 1986), as well as in historical roots of Victorian and Puritan views of the body as unclean (Soth, 2005). Despite these past views, the importance for holistic treatment of persons can be illustrated by Fortsmann, Burgmer, and Mussweiler (2012), who found that when persons were primed with information on mind/body connection they were more likely to indicate greater health seeking behavior than persons who were primed with information expressing separateness of mind and body. Additionally, an international survey of 119 primarily European persons found a positive relationship between body awareness and subjective wellbeing through self-report measures (Brani, Hefferon, Lomas, Ivtzan, \& Painter, 2014).

Mainstream psychotherapy has taken limited steps towards integrating the body into therapy. It has done so through the use of breathing and relaxation techniques (e.g. Brown, Gerbarg, \& Muench, 2013; Dolbier \& Rush, 2012; Lalande, Bambling, King, \& Lowe, 2012), using yoga as a treatment adjunct (e.g. Bilderbeck, Farias, \& Brazil et al., 2013; Froeliger, Garland, Modlin, \& McClernon, 2012; Kinser, Bourguignon, Whaley, Hauenstein, \& Taylor, 2013), and through specialized forms of body psychotherapy (e.g. Langmuir, Kirsh, \& Classen, 2012; Levy Berg, Sandahl, \& Bullington, 2009; Levy Berg, Sandahl, \& Bullington 2010; Rohricht, Papadopoulos, \& Priebe, 2013). 


\section{Yoga and Mindfulness}

There have been many theoretical books published over the years that propose the psychological benefits of yoga, (e.g., Coster, 1972; Kowalski, 2001; Kraftsow, 2002; Levine, 2000; Mishra, 1972), the first of which could be considered The Yoga Sutras of Patanjali. The Yoga Sutras of Patanjali is the foundational text for Raja Yoga, which is a branch of Hinduism that focuses on using meditative concentration to still the mind. Today this text is often associated with the spiritual practice of the physical forms of Yoga such as Hatha (Stiles, 2002). Yoga is a broad term that can be translated as "to come together" or "to unite" and applies to a variety of practices. These practices range from physical poses, to breathing exercises, to meditation, to chanting, to spiritual readings and studies, as well as any combination of these elements (Desikachar, 1995). The majority of the empirical literature thus far has focused on physical, breathing, and meditation practices (e.g. Booth-LaForce et al., 2007; Culos-Reed et al., 2006; Waelde, et al., 2004).

The physical practice of yoga comes in many forms (e.g., Ashtanga, Iyengar, Yin, Kundalini, Vinyasa) that vary in regards to asanas (poses) used and physical pace. However, they all have similar methods of mental practice. For example, the practitioner is urged to stay present during the practice. This means, that while doing yoga, one is supposed to feel the postures and his or her breath without judgment or striving to do it better. Therefore, the physical practice of yoga is also a practice of mental discipline (e.g. Desikachar, 1999; Feuerstein, 1998, Grilley, 2002; Kraftsow, 2002).

"Yoga is experienced in the mind which has ceased to identify itself with its vacillating waves of perception," (Patanjali, trans. 2002). Many discourses on yoga propose that yoga changes a person's state of mind and way of relating to the world (Coster, 1972; Kowalski, 2001; Kraftsow, 2002; Levine, 2000; Mishra, 1972). Through the practice of yoga one is able to 
sharpen his or her focus so as to help minimize distractibility and help him or her maintain a present-focused mindset. A person who practices yoga may be able to break free from repetitive non-present thinking and be able to cultivate a more focused and present mind (Coster, 1972; Kowalski, 2002).

For example, boys with Attention Deficit Hyperactivity Disorder (ADHD) $(n=14)$, saw significant improvements in ADHD symptoms compared to a control group that did not receive yoga (Jensen \& Kenny, 2004). These improvements were observed when the boys were in an unmedicated state after 20,1-hour weekly yoga sessions comprised of breathing exercises and Hatha yoga. Additionally, Shannahoof-Khalsa (2003) conducted two trials testing the efficacy of Kundalini Yoga in the treatment of Obsessive Compulsive Disorder (OCD). In both trials, participants attended weekly one-hour yoga classes for 12 months. The first trial was an uncontrolled pilot study $(n=5)$. In this study, all five participants experienced a significant decrease in OCD symptoms. After seven months, three of the five participants had ceased medication for OCD altogether. One year after the trial had ended, four of the five were off of medication for periods between 9 and 19 months with lasting improvement. The second trial was a controlled study $(n=14)$ consisting of a yoga group and a meditation group. The yoga group experienced significant improvement in OCD symptoms while the meditation group did not. Moreover, three of the yoga participants were able to cease OCD medication after six months of practice.

According to the Yoga Sutras, the practice of yoga can eliminate or diminish physical and emotional pain (Patanjali, trans. 2002). The empirical literature also supports the use of yoga for relief of somatic complaints and emotional stress. For example, there is support for the use of yoga as an add-on treatment for breast and prostate cancer patients (Carlson, Speca, Patel, \& Goodney, 2003; Culos-Reed, Carlson, Daroux, \& Hately-Aldous, 2006). Yoga has been evidenced to aid in pain management and enhance quality of life for this population. This relief 
has also been found in adolescents with Irritable Bowel Syndrome (Kuttner, Chambers, Hardial, Israel, Jacobson, \& Evans, 2006) and women in the peri- and post- menopausal stages (BoothLaForce, Thurston, \&Taylor, 2007).

Women with depression have also found yoga to be beneficial. Kinser et al. (2013) randomly assigned 27 women with major depression to either a yoga or attention control group. Both groups showed significant improvement in depressive symptoms. However, the yoga group showed significantly greater decreases in ruminations compared to the attention control group. In addition, caregivers of people with dementia often experience psychological distress in the form of anxiety and depression. In a study of 12 female caregivers, after participating in yoga classes, scores on measures for depression and anxiety decreased significantly and scores on a measure for self-efficacy increased significantly (Waelde, Thompson, \& Gallagher-Thompson, 2004). In each of these studies, participants practiced Hatha yoga.

Hatha yoga and yogic breathing exercises also appear to reduce levels of cortisol production. Immediately following a Hatha yoga class, participants were found to have a significant decrease in salivary cortisol levels (West, Otte, Geher, Johnson, \& Mohr, 2004). Moreover, Brown and Gerbarg (2005) developed a neurophysiological model for stress and cortisol reduction in people practicing Sudarshan Kriya yoga (SKY). SKY is a form of yogic breathing exercises. Their model suggests that SKY may activate the vagus nerve, which decreases heart rate. Furthermore, SKY may also activate the limbic system, hippocampus, hypothalamus, and amygdala to improve autonomic function and emotional processing. They suggest that these activations may help to stabilize the stress response systems. Persons with Traumatic Brain Injury (TBI) may also benefit from yogic breathing exercises. Ten adults with TBI showed significant improvement in quality of life after participating in breath-focused yoga classes. Participants were assessed multiple times over a 40-week period, however, the number of 
yoga classes attended was not specified (Silverthorne, Khalsa, Gueth, DeAvilla, \& Pansini, 2012).

Previous research has shown the positive effect that physical activity has on stress and affect (e.g. Netz \& Lidor, 2003). There is varying support for the hypothesis that yoga may be superior to other forms of exercise in its ability to decrease stress levels and improve affect. The study by Netz and Lidor (2003) found a significant difference between participants in a yoga class compared to an aerobic dance class. After an academic year in their respective classes, participants in the yoga class showed a decline in anxiety and an increase in subjective wellbeing whereas the aerobic dance participants did not. However, they also compared participants in a swimming class and there was no significant difference between the swimming and yoga participants. The authors speculate that this may be because both swimming and yoga require controlled, cognitively based movements.

West et al. (2004) also found no difference between exercise groups that practiced African dance or yoga. Reductions in perceived stress and negative affect were observed in both groups immediately following a single class session. However, lasting effects from either group are not known. Conversely, when compared to physical training, yoga was found to be more beneficial in a group of people from India with schizophrenia (Duraiswamy, Thirthalli, Nagendra, \& Gangadhar, 2007).

Significant differences have also been seen when comparing yoga and walking. Participants were randomly assigned to either an Iyengar yoga $(n=19)$ or walking condition $(n=$ 15). They were $18-45$ years old, did not qualify for any axis I diagnosis, and had no medical history that would contraindicate brain scans. Persons who had practiced yoga in the past three months or who had a history of one yoga session or more for four or more weeks were excluded. The yoga group received weekly one hour Iyengar yoga classes taught by a certified instructor. 
Walking group participants walked the perimeter of the gym as a group at a rate of $2.5 \mathrm{mph}$ for one hour. These two group conditions were deemed to be metabolically equivalent per the American College of Sports Medicine list of metabolic equivalents.

GABA levels were measured through magnetic resonance spectroscopy (MRS). MRS was administered at baseline, after the 12-week intervention, and immediately following one additional yoga/walking intervention. Subjects were administered the Exercise Induced Feeling Inventory (EIFI) and the Speilberger State-Trait Anxiety Inventory (STAI) prior to their first MRS and at weeks four, eight, and 12 of the intervention.

Yoga participants reported significantly greater improvements in mood as measured by the EIFI and a significantly greater decrease in anxiety as measured by the STAI compared to the walking group. Neither group showed significant changes in GABA levels after completing the 12-week intervention. However, the yoga group demonstrated increased GABA activity immediately following the additional yoga class whereas the walking group did not demonstrate increased GABA when MRS was done immediately following the walking activity. Since persons with conditions that may impact GABA, such as depression and anxiety, were excluded from this study the authors speculate that persons who are experiencing low GABA levels may show different long-term results than persons whose GABA levels are already within the normal range (Streeter, Whitfield, Owen, Rein, Karri, Yakhkind,...Jensen, 2010).

As one progresses in his or her practice of yoga, it has been theorized that he or she will develop greater self-awareness and will begin to interact with the world differently (Coster, 1972; Kowalski, 2001; Kraftsow, 2002; Levine, 2000; Mishra, 1972). In his book, The Positive Psychology of Buddhism and Yoga: Paths to a Mature Happiness (2000), the psychologist Marvin Levine describes his own changes that he attributes to his yoga practice. Levine (2000) states that his practice has made it much easier for him to adapt and be at peace in adverse 
circumstances. Similarly, in a sample of 52 yoga practitioners in Massachusetts, advanced Hatha yoga practitioners (more than five years of practice) showed significantly greater levels of mindfulness than beginning practitioners (Brisbon \& Lowery, 2011).

Mindfulness is a broad term that can refer to a number of different attentional practices. In psychotherapy, the most common form of mindfulness used is the mindfulness used in the Mindfulness-based Stress Reduction (MBSR) program (Kabat-Zinn, 1990). This form of mindfulness, based on Buddhist practices, encourages the client to notice the unfolding present moment without judgment (Dorjee, 2010). MBSR and similar mindfulness interventions have been used effectively with a variety of populations such as cancer patients (Campbell, Labelle, Bacon, Faris, \& Carlson, 2012), veterans (Serpa, Taylor, \& Tillisch, 2014) and persons with depressive and anxiety (Hofmann, Sawyer, Witt, \& Oh, 2010).

Mindfulness practices such as that practiced in MBSR have led to improvements in both psychological and physical health (e.g. Carmondy \& Baer, 2008; Keune \& Forintos, 2010; Prazak, Critelli, Martin, Miranda, Purdum, \& Powers, 2012). Nyklíček \& Kuijpers (2008) randomly assigned 60 participants with symptoms of distress to either an MBSR or wait-list control group. Those in the MBSR group showed significant reductions in perceived stress and significant improvements in positive affect and quality of life when compared to the control group. When mindfulness was included as covariate, these results became statistically nonsignificant. This suggests that increases in mindfulness may mediate the positive effects of MBSR. Similarly, Carmondy and Baer (2008) also found increases in mindfulness to mediate the relationship between meditation practice and improvements in psychological functioning.

There are multiple neurocognitive correlates for mindfulness practices such as yoga and meditation. For example, seven hatha yoga meditation practitioners and seven controls with no experience of yoga or meditation demonstrated differences in the method of completion of an 
Affective Stroop Task. In this study, practitioners reported in engaging in yoga meditation every day for an average of five years. Participants' state and trait affect was assessed and fMRI imaging was collected while participants completed an Affective Stroop Task.

Participants did not differ in state or trait affect nor did they differ in task completion during the Affective Stroop Task. However, fMRI imaging demonstrated that how participants completed the task did differ. Practitioners did not experience increased activation in dorsolateral prefrontal cortex when exposed to negative versus neutral stimuli, whereas controls did. Instead practitioners demonstrated greater activation in the ventrolateral prefrontal cortex. Also, in controls amygdala activation was negatively correlated with positive mood self-report following the task. This relationship was not demonstrated in practitioners. Controls also demonstrated a reciprocal pattern of executive-limbic response during viewing negative emotional images while practitioners did not (Frolinger, Garland, Modlin, \& McClemon, 2012).

Age related brain differences have also been seen between mindfulness practitioners and non-practitioners. In one study, the brains of 47 middle-age participants were compared. They were 16 Kripalu yoga practitioners, 16 Vipassana meditation practitioners, and 15 controls who had no experience with either yoga or meditation. The participants were matched for age, gender, education, race, and handedness. Persons who had past/current neurological conditions or who were being treated with psychotropics were excluded. Mindfulness, intelligence, and mental status were assessed and participants were also asked to report frequency and duration of physical exercise and cognitive activities such as reading, writing, solving puzzles, etc. Brain imaging was collected on an MRI scanner and was analyzed using graph theory.

Yoga and meditation practitioners both had significantly greater mindfulness scores than controls. They also demonstrated decreased age related declines in fluid intelligence and MRI imaging showed that both of the practitioner groups had stronger small-world architecture with 
greater network integration. The yoga and meditation groups did not significantly differ from one another (Gard, Taquet, Holzel, de Montjoye, Brach,...Lazar, 2014).

Neither of these neuroscience studies can provide a causal link between mindfulness and the observed brain differences. It could be that the brain differences already existed and predisposed practitioners to be interested in mindfulness practices. Future controlled trials on mindfulness practices with brain imaging could help increase our understanding of these neurocognitive correlates. There are, however, known differences in brain activation when engaged in a mindfulness task versus other tasks.

In a meta-analysis of 46 studies that performed whole brain MRI analysis of healthy adults engaged in a meditation task without pharmacological manipulation, several brain regions show more activation during meditation versus control tasks. These included the caudate nuclei, the middle and superior temporal gyrus, the precentral gyrus in the left hemisphere, the anterior cingulate cortex, the superior frontal gyrus, the parahippocampal gyrus, the angular gyrus, the middle occipital gyrus in the right hemisphere, and the left posterior cerebellum. These areas relate to tasks such as self-relevant information, self-regulation, focused problem-solving, adaptive behavior, monitoring internal body states, reorienting attention, and processing experiential material. They also found that in general, meditation practitioners had more grey matter in the right anterior cingulate cortex in the frontal lobe, in the left and medial frontal gyrus, in the left precuneus, in the fusiform gyrus, and in the right thalamus. Based on this meta analysis, these results were typical regardless of type of meditation used (Boccia, Picardi, Guariglia, 2015). Mindfulness practices such as meditation and yoga appear to positively impact a variety of mental health outcomes (e.g. Carmondy \& Baer, 2008; Kinser et al., 2013). They also appear to relate to a number of neurological differences (e.g. Boccia, et al., 2015). 


\section{Body Psychotherapy}

Body psychotherapy is a broad term for a variety of psychotherapeutic approaches that seek to use the body as a vehicle for healing. These therapies help clients tune into body sensations, use kinetic movements to express and work through emotional content, and help clients become more self-aware of their internal environment (Burns, 2012). Therapists who identify as body psychotherapists may have training in one particular method (e.g. Core Energetics, Bioenergetics, Hakomi) or may have a more generalist training in somatic psychology. The United States Association of Body Psychotherapy (USABP) is a professional organization devoted to furthering the practice of body psychotherapies. The USABP says in it's mission statement: "The United States Association for Body Psychotherapy believes that integration of the body and mind is essential to effective psychotherapeutic health," (USABP, 2015).

Research on most forms of body psychotherapy is in its infancy, however so far the results indicate that these approaches may be efficacious in the treatment of clients. For example, Langmuir, et al. (2012) hypothesized that Ogden's Sensorimotor Psychotherapy (OSP) would decrease states of hyper- and hypo- arousal and dissociation in female trauma survivors. OSP is a therapeutic approach that seeks to integrate cognitive, affective, and somatic responses through mindfulness skills and exploration of physical responses to changes in movement and posture. They recruited 10 women ages 31-65 that have a history of interpersonal trauma to participate in 20 group sessions. The participants showed significant improvement in body connection and decrease in dissociative experiences. Rohricht, Papadopoulos, and Priebe (2013) randomly assigned 30 patients awaiting treatment for chronic depression and dysthymia into two groups. One group was placed into a Body Psychotherapy Treatment (BPT) group program that included sensory awareness activities to improve body awareness, physical grounding techniques, physical strength building exercises, and body oriented psychological work designed to express unmet 
needs and overcome trauma as applicable with patients. The other group was placed on a waitlist for the program and served as an experimental control. Analysis of covariance tests showed significant improvement in depressive symptoms after BPT, however there were no significant changes in self-esteem or quality of life. The control group showed significant improvement in depressive symptoms after undergoing BPT as well. This study had a large attrition rate, which when coupled with the small sample size may explain why there were no significant changes in quality of life despite improvements in depression. Levy Berg, Sandahl, and Bullington (2009)

also found Affect-Focused Body Psychotherapy (ABP) to be as effective as treatment as usual for persons with Generalized Anxiety Disorder. This same sample was interviewed in a follow-up qualitative study that found that the perceived effectiveness of the ABP by participants was highly influenced by their understanding of and belief in mind/body unity (Levy Berg, Sandahl, \& Bullington, 2010).

Unfortunately, all of these studies are limited by small sample sizes and reliance on selfreport measures. Despite the limitations and inability to generalize findings, these studies lend support to the potential efficacy of including the body in psychotherapeutic treatment.

\section{Phoenix Rising Yoga Therapy}

Phoenix Rising Yoga Therapy (PRYT) (Lee, 1997) is a one-on-one form of mind/body therapy that integrates body movement, practitioner-assisted yoga poses, touch, and non-directive dialogue to facilitate client growth and change. It is different from typical Western-style yoga classes that may have an emphasis on fitness or form and deviates from other types of Yoga Therapy that seek to treat specific conditions (FAQS, 2014). Unlike the body psychotherapies discussed above, those trained in PRYT do not have to have an advanced degree and PRYT is not considered psychotherapy. However, PRYT helps clients in a similar manner through increasing awareness of the body and sometimes using the body as a vehicle to express and work through 
mental and emotional content. PRYT is not intended to diagnose or treat any condition (Phoenix Rising Yoga Therapy, Inc., 2008).

In the book, Phoenix Rising Yoga Therapy: A Bridge from Body to Soul, Micheal Lee the founder of PRYT proposes his theory for the modality. He states that PRYT allows the recipient to attune to a deeper level of knowing that she or he can then live from. This is done by becoming fully present to one's body and experience and then using that knowledge to promote learning and growth. The recipient learns to know and trust their own answers instead of seeking guidance from people or other outside sources. The body in PRYT acts as the vehicle to unlock inner wisdom and present moment experience so that the recipient can learn to live more fully from their own unique process (Lee, 1997).

Lee's theory has some similarity to the benefits of yoga expressed in The Yoga Sutras of Patanjali. This text states that when Yoga is truly experienced, one's awareness is able to rest in its true nature so that the True Self can be known and experienced (Patanjali, trans. 2002).

Previous research has examined the training of PRYT practitioners (Kokinakis, 1996) and the outcome of the manualized 8-week PRYT group called, "Turn Stress into Bliss" (Martin, 2010). This group organizes yoga classes around specific themes for reflection. The themes are: befriending your body, becoming more aware, acceptance, choice, discernment, discovering personal truth, truth in action, and flow. Martin (2010) found that participants in the 8-week PRYT group significantly strove towards unattainable goals less frequently and reported significantly less stress than persons in the control group. This study is limited by its small sample size of nine participants who self-selected to be in either the experimental $(n=6)$ or the control group $(n=3)$. The study had a high attrition rate with an original sample size of 20 . Furthermore, persons already attending yoga classes were targeted for sampling and this may have skewed the results due to their previous familiarity with and interest in yoga. 
No studies to date have examined individual PRYT sessions. According to the PRYT website, PRYT helps clients increase self-awareness and self-acceptance and that through these increases, clients are able to change old behavioral patterns and beliefs (Why PRYT, 2012). Additional benefits listed in the PRYT training manual include: deep relaxation, greater emotional stability and mental clarity, empowerment and self-esteem, greater body awareness, and stress reduction (Phoenix Rising Yoga Therapy, Inc., 2008). Evidence to support these claims is merely anecdotal. 
Appendix B:

Philosophy of Phenomenology

Phenomenology is situated within the belief that scientific inquiry into human experience must take into account the actual lived experience of the participants. The groundwork for the philosophy behind phenomenology can be found in the work of such prominent philosophers as Descartes, Kant, and Hegel. Husserl then synthesized these philosophical underpinnings into Transcendental Phenomenology (Moustakas, 1994; Van Manen 2014).

Descartes firmly believed in the primacy of consciousness. He saw science as a subjective process in which objective realities only existed through mental representations and that therefore all of reality is in fact subjective. Similarly, Kant believed that all knowledge must conform to experience. He saw three things as responsible for how we come to have knowledge: the senses, imagination, and apperception. Descartes and Kant both shared the belief that selfevident knowledge truly exists whereas external things only exist in phenomenal states (Moustakas, 1994).

Hegel, who succeeded Kant as prominent philosopher, moved away from Kant's belief that simple consciousness is sufficient for understanding the world. He posited that in order to study anything we are actually studying consciousness. Hegel stated that in order for things to be studied we must name them and make them universal concepts but by doing so we destroy the thing itself and instead create an understanding of the thing. Sense-experience, as delineated by Kant, is the simplest form of consciousness and from sense experience we can step back to come to a place of sense certainty. Sense certainty is direct awareness of present moment experience, however, the experiencer and that which is being experienced mediate even that experience. Furthermore, sense certainty can never be communicated to another due to its immediate and 
personal experience. Language abstracts and annihilates the sense certainty but language is needed in order to make the knowledge universal (Van Manen, 2014).

Husserl's Transcendental Phenomenology emphasizes subjectivity and discovering the essence of pure experiences. He sought to make phenomenology into a rigorous science that would fill the gaps created in other forms of science by neglecting to reflect on the meanings of the knowledge they gained. He stated that the natural sciences also fell short in only viewing the physical as real. Therefore, they were actually not objective in that they had placed a subjective value system on science (Van Manen, 2014). Phenomenology seeks to understand the essence of an object or experience by creating textural descriptions through a reflective process that include thoughts, feelings, ideas, etc. The person is seen as the source for gaining knowledge, as it is the person's life-world experience that we seek to understand. Thus, the person can create their textural descriptions to try to share their life-world with others and through repeated viewing and examination of this data we can come to understand a phenomena (Moustakas, 1994).

\section{Phenomenology in human science research}

Phenomenology seeks to find the meanings behind human experience. It seeks to do this through descriptions that are committed to retaining as close as possible the original qualities of the experience. These descriptions are vivid and accurate depictions of what appears in consciousness (Moustakas, 1994).

It is understood that the phenomenological question is of interest and concern to the researcher and that the researcher has a personal interest and opinions on the topic. The researcher must identify and bracket her or his bias. However, at all points in the inquiry process intersubjectivity is present between the observer and the observed, and subject and object are integrated (Moustakas, 1994). 
The primary source of data in phenomenological human science research is the phenomenological interview. This interview seeks to create a lived-experience description. This description is not merely a narrative but is instead an experiential account of an experience as it was lived through and not merely as it is remembered. Another form of data often used is the observation of lived experience. This is achieved through close observation in which the researcher participates in the person's life-world. The observer must take care in order to be as close as possible to the person being observed while also being able to step back from and reflect upon the meanings of the situation (Van Manen, 2014). 


\section{Appendix C:}

\section{Phenomenological Interview Questions}

1. What was your reaction as you read the ad for participation for this study?

2. What did you notice about your thoughts, feelings, and experiences as you considered becoming a participant?

3. What led you to volunteer as a participant?

4. How were these decision making factors showing up in your day-to-day life at this time?

5. What were your thoughts, feelings, and expectations as you arrived for your first session?

6. What was your actual experience of the first session?

7. What did you notice in your day-to-day life after receiving the first session?

8. What did you notice in your day-today life as you continued receiving sessions?

9. Tell me anything you would like that you noticed and experienced throughout the subsequent sessions.

a. This will be followed by probes depending on answers provided

10. What was it like to journal after the sessions?

11. How has receiving PRYT affected how you are currently living?

12. What are your thoughts and feelings about PRYT now that you have received 5 sessions?

13. What stands out to you the most about your experience participating in this project?

14. What would you most like to communicate to someone who is considering PRYT?

15. How does experiencing PRYT compare or not compare to experiencing other healing modalities you have tried, if any? 
Appendix D:

PHOENIX RISING YOGA THERAPY

CLIENT HISTORY FORM

Today's date:

Name

Age

Ht.

Wt.

Address

Phone

Current Occupation

Race/Ethnicity Gender Sexual Orientation

10. Please list the type and approximate date(s) of any other bodywork modalities you have received (i.e. massage, shiatsu, acupuncture):

2. Current exercise program:

3. Experience in yoga and/or meditation:

4. Briefly outline your personal support system (i.e., family, friends, health care providers, groups):

5. What do you hope to receive from Phoenix Rising Yoga Therapy? 
6. Is there anything else you'd like me to know before we start our work?

7. Please fill in the following section for any condition for which you have been treated in the past two years.

Physician: -

Psychotherapist:

Chiropractor:

Psychiatrist:

Homeopathic or Naturopathic Physician:

Other (please list):

8. Please list below any prescription or non-prescription medication you're taking:

9. Please list any history of surgeries, major illness, chronic conditions, accidents, injuries, or anything that might be relevant to doing Phoenix Rising Yoga Therapy which were not listed previously: 
10. Please check any condition that applies to you:

Addiction Recovery: Length of time (days, months, years) in recovery:

Arthritis

Asthma

Bulging or Herniated Disc

Chronic Fatigue Syndrome

Contact lenses (check if you are wearing currently)

Degenerative Disc Disease

Depression

Anxiety

Eating Disorder

Emphysema or other breathing problem

Fibromyalgia

Fatigue

Fused Vertebrae

Heart Condition

Hernia

High Blood Pressure

History of abuse or trauma

Low Blood Pressure

Multiple Sclerosis

Osteoporosis

Pregnancy: How many weeks? 
Appendix E:

\section{Oklahoma State University Institutional Review Board}

Date:

Tuesday, June 30, 2015

IRB Application No

ED1591

Proposal Title:

Phenomenological inquiry into Phoenix Rising Yoga Therapy

Reviewed and

Processed as:

Expedited

Status Recommended by Reviewer(s): Approved Protocol Expires: 6/29/2016

Principal

Investigator(s)

Jenilee Sneed

Tonya R. Hammer

4701 N Washington Ave Apt

700 N Greewood Ave

Stillwater, OK 74075

Tulsa, OK

The IRB application referenced above has been approved. It is the judgment of the reviewers that the rights and welfare of individuals who may be asked to participate in this study will be respected, and that the research will be conducted in a manner consistent with the IRB requirements as outlined in section 45 CFR 46.

[ The final versions of any printed recruitment, consent and assent documents bearing the IRB approval stamp are attached to this letter. These are the versions that must be used during the study.

As Principal Investigator, it is your responsibility to do the following:

1.Conduct this study exactly as it has been approved. Any modifications to the research protocol must be submitted with the appropriate signatures for IRB approval. Protocol modifications requiring approval may include changes to the title, PI advisor, funding status or sponsor, subject population composition or size, recruitment, inclusion/exclusion criteria, research site, research procedures and consent/assent process or forms 2.Submit a request for continuation if the study extends beyond the approval period. This continuation must receive IRB review and approval before the research can continue.

3.Report any adverse events to the IRB Chair promptly. Adverse events are those which are unanticipated and impact the subjects during the course of the research; and

4.Notify the IRB office in writing when your research project is complete.

Please note that approved protocols are subject to monitoring by the IRB and that the IRB office has the authority to inspect research records associated with this protocol at any time. If you have questions about the IRB procedures or need any assistance from the Board, please contact Dawnett Watkins 219 Scott Hall (phone: 405-744-5700, dawnett.watkins@okstate.edu).

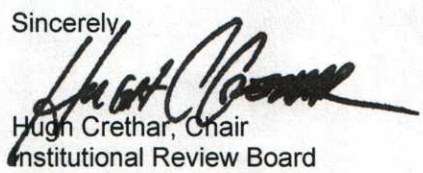


Appendix F:

ADULT CONSENT FORM

OKLAHOMA STATE UNIVERSITY

Phenomenological Inquiry into Phoenix Rising Yoga Therapy

Jenilee Sneed, MA. PRYT-P, \& Tonya Hammer, Ph.D., School of Applied Health and Educational Psychology

Phoenix Rising Yoga Therapy (PRYT) is a one-on-one form of mind/body therapy that integrates body movement, practitioner-assisted yoga poses, touch, and non-directive dialogue to facilitate client growth and change. Anecdotally, PRYT reports that it has helped clients reduce stress, increase self-awareness, and to find their own answers to life problems (Lee, 1997) and a PRYT group approach showed improvement in stress. However, individual PRYT sessions have not been formally investigated. This study seeks to gain understanding about how client's experience PRYT sessions and how these sessions impact their lives.

\section{PROCEDURES:}

You will received 5, 90-minute individual PRYT sessions from Jenilee Sneed, a certified Phoenix Rising Yoga Therapy Practitioner. These sessions will take place in her office located at 1324 S Main St. Unit A Stillwater, OK 74074. Sessions will occur once a week to once every two weeks depending on scheduling.

Prior to beginning sessions, the researcher will schedule a meeting with you to answer any questions you may have. If you decide to participate in the study at this time, you will be asked to complete intake paperwork that includes demographic and health history information, a liability waiver, and an informed consent form stating the nature of PRYT. This initial meeting will take approximately $30 \mathrm{~min}-1 \mathrm{hr}$.

Sessions will be videotaped as a source of data to be coded for themes. You will be asked to journal after each session in the provided notebook. You may also journal more frequently if you choose. After completing all 5 sessions, you will be asked to participate in a 1-hour interview about your experience. Interviews will be audio-recorded as another source of data to be coded for themes.

After the data is analyzed, you will be provided with the findings along with your deidentified data to check the accuracy of results found. You will have one week to review data and provide feedback. It is requested that the data be returned within one week to the researcher.

\section{FEE FOR SERVICES:}

There will be no charges incurred by participants for their involvement in the sessions and or study. 


\section{RISKS OF PARTICIPATION:}

Risks associated with participation in this research study include the potential for increased psychological distress that can be experienced during the course of any healing modality. If you experience any psychological discomfort please share your concerns with Jenilee Sneed. You will also be provided with crisis-line and community psychological services information.

\section{BENEFITS OF PARTICIPATION:}

Phoenix Rising Yoga Therapy is sought by many to help them address life problems, improve self-awareness, and create positive change. However, there is not much research to date on this modality. Your participation will increase our current knowledge of the potential usefulness of PRYT.

\section{CONFIDENTIALITY:}

The records of this study will be kept private. Any written results will not include information that will identify you. Paper data such as the intake paperwork and journals will be stored in a locked file within a locked office that only the PI will have access to. Video data, audio data, and electronic transcripts will be stored in password-protected files on a password-protected computer and only the PI and advisor will know these passwords. The files will also be backed up on a password-protected flash drive that will be stored in the locked filing cabinet as well. All information will be de-identified and faces will be blurred in the videos before data is shared with the external reviewer and/or the PRYT practitioner who will do the authenticity check. The data will be emailed to the auditor and practitioner in encrypted files and folders and the reviewer/practitioner will be asked to delete all files after verification.

All data will be destroyed five years after results are published with exception of the intake paperwork. Intake paperwork will be destroyed seven years after you stop receiving PRYT sessions from Jenilee Sneed.

\section{CONTACTS :}

You may contact any of the researchers at the following addresses and phone numbers, should you desire to discuss your participation in the study and/or request information about the results of the study: Jenilee Sneed, MA, PRYT-P, 1324 S Main St. Unit A Stillwater, OK 74074, (424) 272-0747, or Tonya Hammer, PhD, 2437 Main Hall OSUTulsa, Tulsa, OK 74106, (918) 594-8309. If you have questions about your rights as a research volunteer, you may contact the IRB Office at 223 Scott Hall, Stillwater, OK 74078, 405-744-3377 or irb@okstate.edu

\section{PARTICIPANT RIGHTS:}

I understand that my participation is voluntary, that there is no penalty for refusal to participate, and that I am free to withdraw my consent and participation in this project at any time, without penalty.

Medical Liability Statement: 
In case of injury or illness resulting from this study, emergency medical treatment will be available 24 hours a day at Stillwater Medical Center Emergency Room located at 1323 W 6th Ave, Stillwater, OK 74074, (405) 372-1480. No funds have been set aside by Oklahoma State University to compensate you in the event of illness or injury.

\section{CONSENT DOCUMENTATION:}

I have been fully informed about the procedures listed here. I am aware of what I will be asked to do and of the benefits of my participation. I also understand the following statements:

I affirm that I am 18 years of age or older.

I affirm that I have agreed to be video-taped and audio-recorded for purposes of this study.

I have read and fully understand this consent form. I sign it freely and voluntarily. A copy of this form will be given to me. I hereby give permission for my participation in this study.

Signature of Participant

Print

Date

I certify that I have personally explained this document before requesting that the participant sign it.

Signature of Researcher

Print

Date

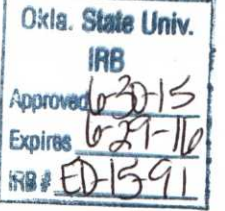


Appendix G:

Amber Interview

C: Alrighty. So I'm here with Amber and we're gonna go ahead and do her interview um if I can get the mic set up um for Jenilee Sneed's dissertation follow-up. Um so just jumping right in um what was your reaction as you read the ad for participation for this study?

A: Well uh I thought it was very interesting. Um. I wanted to see uh if it could help me, I've always had anxiety and I thought it might be something that could help me deal with it.

C: Right. Ok. And um you know did you notice any thoughts or feelings or any sort of experiences as you considered becoming a participant?

A: Um I was just really excited to get to do something different. I like trying new things. Pretty excited.

C: Cool. Cool. And you know any uh any thoughts that kind of came along with the feeling of excitement?

A: Um I mean I was a little bit nervous just I mean because I didn't know what it would entail.

C: Mm-hm. Yeah. And so what kind of got you over that, over that hump to you know to actually volunteer and become a participant?

A: Well um mostly um because the excitement to try something new to see if it could help me deal with my anxiety and nervousness.

C: Ok. So you mentioned your anxiety a couple times now and that you were kinda hoping that this would be beneficial for it.

A: Yes. 
C: Alright. So how were these types of decision making factors showing up in your day to day life?

A: Um well I continued to meditate after we stopped and um that is really, it's really helped me to control my thoughts, my negative thoughts and anxiety and uh fear. And I actually started exercising again, which was a big deal because I hadn’t since I broke my ankle a couple years ago.

C: Ok. And what exercises do you do?

A: Just biking right now.

C: Ok, alright. It's better for your knees (A: Yeah). So um so is this something that like, you know you kind of you said the excitement kind of gave you the ability or the desire to try something new kind of made you want to be a part of this study. Is that something you approach a lot of other situations with?

A: Yes, I love trying new things and being busy.

C: Ok. Being busy. Alright. Um. So what were you thoughts, feelings and expectations as you arrived for your first session?

A: Um I was a little but nervous. Um. I, I expected that um you know it would be something new and something that I would need to get used to. And I expected it to be very clam. I did not expect it to be as physical.

C: Mm. Can you elaborate on that a little bit?

A: Um well since I broke my ankle and injured hip years ago, I've had a fear over doing anything physical besides walking so.

C: Ok. And all the stretching I'm sure kind of provoked that fear just a bit. 
A: Yes.

C: So after actually going to the session, what was the actual experience like as opposed to what you kind of perceived it might be like?

A: Um I had a much more emotional and physical response than I thought I would have.

C: Ok. Would you care to elaborate on that a bit?

A: Um sorry if I break, my, um we talked a lot about my daughter and her hearing loss (voice begins to break with emotion) and I knew that I always felt bad about it but I didn't know how bad. And uh how much I focused on it.

C: Right. So exploring those feelings definitely brought up some emotions for you.

A: Yes. And the physical, I didn't expect, um, I had a lot of uncontrollable shaking when she would move my legs. And I didn't expect that, I didn't know how much fear I had.

$\mathrm{C}: \mathrm{Mm}$. And is that kind related to your injuries?

A: Yes. Ever since I, I fell really bad and developed gout. And it and I broke my ankle and injured my hip at the same time.

C: Wow that sounds like quite the injury.

A: Two years ago so.

C: Wow, I'm sorry.

A: Oh that's alright.

C: So what did you notice in your day to day life after receiving your first session?

A: Um I became much more aware of negative thoughts. 
$\mathrm{C}: \mathrm{Mm}-\mathrm{hm}$. Were you able to like kind of combat those a little bit or?

A: Yes, I found it, when I realized what a huge space that I gave it in my mind. I was able to address them and move on much quickly than just thinking about it over and over all day.

C: I bet that's very nice to be able to do.

A: Yes.

C: So as you continued receiving sessions did you notice anything else in your day to day life or did you do, were you able to do that better or..?

A: Um yes I , like I said I hadn't exercised in two years and I used to be an athlete so it was really hard for me to not do anything. So um but I was so scared of getting injured again. And I actually, after I started I actually started biking again, I started swimming again, and I started walking with my kids.

C: Great. So you've gotten back to being active again.

A: Starting to. Not as active as I used to be.

C: Right.

A: More low impact.

C: Mm-hm. Um so tell me anything that you'd like for me, or tell me anything that you noticed or experienced after subsequent sessions, after the first.

A: Um after the first time I realized as I continued I got, the emotional side got much easier for me after getting those thoughts out I got much more calm and better at that side of things. And after being afraid that I was gonna hurt myself and it never did hurt afterwards, I got much more I guess brave about doing the more physical things. 
C: Yeah. (inaudible) So the physical things got easier as well I'm guessing.

A: Yes. Yes. I shook a lot less, I still, it was only one leg, I would still, but it got less and less.

C: So what was it like to journal after the sessions?

A: Um I'm not a very good writer so that was a challenge for me to put my thoughts into words um I got through it. But I did realize that you know I thought of more things that maybe I hadn't thought of during session the session that came up.

C: Like what?

A: Um well see like when I would be writing and I would talk about how I felt and then I was like oh I did kind of feel like I guess I didn't really feel that it, I didn't realize it at the time.

C: Ok kind of these, so being able to write out these feelings definitely helped you become more aware of them (A: Yes) and their presence. So how has receiving this treatment, you know, effected how you're currently living?

A: Much. Uh I really liked it a lot. I do feel that I'm much more aware of my negative thoughts about myself or about just fears about my kids. And I really like feel like I'm better at not giving them a voice and not giving them space in my mind.

C: Right, the negative thoughts.

A: The negative thoughts. Yes.

C: And so what are your thoughts and feelings about this type of therapy modality after receiving five sessions of it?

A: I think it's really neat. I, I really liked it. Um I thought it helped me a lot. 
C: Ok. Alright. And so what stands out most about the um you know participating in this project as a whole?

A: Um, let me see, what stands out the most...

C: Yeah, what do you remember the most when you look back on this project?

A: Well, the most I remember is how I didn't realize what effect my thoughts were doing to my physical self. I kind of thought that they were two separate things and then I realized how much my fear and anxiety over everything was negatively effecting my body.

C: With the shaking and the fear of exercise and things like that? Is that what you're referring to?

A: Um, yes, yes. And also just how tense my shoulder my shoulders were and um little things like that. Um uh I would have much more gout attacks.

C: And have those lessened since then?

A: Yes. yes. I haven't had an ulcer or a gout attack since I started. I used to have them about once a month.

C: Wow that's great. Um like to not have, not that you had them once a month.

A: Yes, yes I understood. I understood.

C: Ok just wanted to clarify. Like gout is great, ulcers are great! (both laugh) So what did you like most or what would you most like to communicate to someone who is considering this type of therapy? What would you like for them to know?

A: Um that it's very helpful. Um to you know be prepared to open yourself up physically and emotionally. 
C: And I imagine that uh the physically part is not necessarily something you'd like think of with traditional therapy. (A: yes) Uh it's kind of a unique component of the (A: yes). Um and so how has this experience compared to other healing modalities that you have tried?

A: Um I think it's very helpful. Um just the action of my eyes are closed helped me open up more.

C: Ok, alright. And so um you know would you say its comparable would you say it's more or less effective or..?

A: It's different. It's just different. Um I've done traditional therapy before and not that it's better or worse it's just kind of a different avenue. It helped me mostly um realize that my mind and body were connected as opposed to traditional therapy I've thought of working mostly from the inside.

C: Yeah. You've hit on that mind/body connection a couple times.

A: Yeah that's what I took away most.

C: Yeah. Yeah. Well you know we kind of blazed through that so is there anything else you'd like to add as we wrap up?

A: Um. No I really enjoyed my experience, I think I learned a lot about myself and I think it was very beneficial to my life.

C: Good, I'm glad. I'm glad. And Jenilee will be glad to hear that as well I'm sure. Alright well we'll just go ahead and stop right there then.

\section{Elizabeth Interview}

C: So the first question right off the bat is what was your reaction as you read the ad for participation in the study? 
E: Um I was very, I was intrigued. I had never thought about using therapy, not therapy, yoga as therapy outside of maybe physical therapy. Um so I wondered how one would incorporate the poses and the meditation and any other philosophies into a discussion of um what people are experiencing, going through.

C: Right right. So didn't really see it as um a thing that could merge I guess the mental and the physical at first. Now when you were considering.

E: I was, I was looking at it from purely a inquisitive I don't know almost academic endeavor.

C: Ok. Um I mean did you notice any thoughts or feelings that you experienced when you were considering becoming a participant for the study.

E: Um I mean my major thought was maybe this would help get back into my regular yoga practice. Which had kind of fallen to the wayside because of newborns.

C: That'll do it right?

E: Yeah.

C: Alright any feelings that came up?

E: I was I mean I was excited. Um I mean the biggest, the biggest feeling was just being intrigued and curious.

C: Alright. So just kind of this uh I guess uh excitement of the unknown almost.

E: Yeah. Something new to try, let's try it.

C: So what led you to finally make that decision to volunteer?

E: Spur of the moment. I just, said you know why not? 
C: So um you kind of just read it and were like I'm gonna do it.

E: Yeah.

C: Wow. (inaudible and then laughter) Ok alright. So um how I mean does, is that something like that kind of uh decision process that go through in like your day to day life?

E: Just the something new, let's do it?

C: Yeah.

E: Um when it when it comes to my life outside of work, then yeah. Um I I try to re- it's one of those things that I try really hard to teach my kids you know it's all about the experiences and and trying, you gotta try, you gotta try to the new food, you gotta try the new sport. I don't care if you don't like it, gotta try it once. Cause otherwise you wont know if you like, if you'll like anything. And technically I kind of do, I do that with my with work a little bit too. Mainly with going to conferences I'm like oh that sounds like a great conference "click" lets apply. (they continue to discuss conference attendance and other unrelated activities...)

C: So um when you know switching gears a bit, when you arrived to your first session what thoughts and feelings and expectations did you have at that time?

E: Um. Feelings was a little bit nervous and anxious. I didn't know how it was going to go. Uh. I always get that feeling when I do something new. It's um and so while I do all of those, what as you say freeing things, have a freeing attitude yeah I get a lot of anxiety once it happens that fist time. Um so but it, so I was nervous but um excited a little bit. Uh expectations, I was I mean I was expecting that we would do, that it would be more like a regular yoga class but maybe we'd talk through the poses.

C: Ok. And so how does that compare to what you actually experienced? 
E: Um. I was expecting slightly more um a faster pace. And it was very slow and there was a lot of emphasis on meditation rather than movement a lot of times. And we didn't do too many what I would say were classic poses. There was a lot of sitting cross legged, um sitting on on my knees, occasionally I would stand. A lot of times I did a lot of laying down.

C: Right and uh were you comfortable with those things or um..

E: It was a little, it was a little difficult. I mean through all five of the sessions because I'm used to being up and moving and going and it was, the only time that I ever really stop and slow down is for bedtime. And so we had a lot of issues where my where my um comments were you know she'd ask me how I felt and I'd say well I'm tired and we had a lot of issues of of my attempting to fall asleep on her. And you know I have that issue anyway when I do yoga in a class I keep um when we I'll be fine through all the poses and then well do the final sivasana or corpse pose and where you do a relaxing let's slow down and calm down and I'd fall asleep in class. So we had a lot of issues with me attempting to fall asleep on her.

C: Well that makes sense since you said you don't fall asleep until bedtime and your body's like oh its sleep time now.

E: So I had a lot of yawing and I felt really bad every time because I did know she was expecting me to be more talkative or be more awake. There was a lot of yawning.

C: Alright. Ok. Um so what did you notice in your day to day life after receiving your first session? Anything..

E: Um. Ah it's I mean it started it did make me think more about yoga and wanting to get involved but it also made me think more about meditation, which I don't I don't do on a daily basis. Um. And I looked at different other types of meditation. Um that I wondered if would help, help me a little better. Cause I I struggled a little bit. I mean I enjoyed the sessions but they were 
a little long for constant, constantly being focused on meditation. Um. I don't you know since I'm constantly on the go I it's it's hard to do meditation consistently for more than thirty minutes. I can do I can do you know ten minutes and then a break and then ten minutes and a break or I can do thirty minutes straight. But you know the sessions were an hour, hour and fifteen, hour and thirty, I can't seem to remember. So after about thirty, forty minutes I started going down really fast, going down hill. That was when I started falling asleep and um and so I I I worked on, I've been working on um walking meditation instead. Where I meditate while walking.

C: Right right. So that's something you've kind of incorporated after the yoga sessions.

E: Yeah so I usually, I have to walk form where I park my car to my building, which you probably do too, and I park way out in westwood and so it takes me about fifteen, takes me about fifteen minutes to walk. And so I use that time to on the way to class I prepare for class and get mentally ready for it, and then after after work and office hours I use it to calm back down and to switch gears to being with the kids in the evening. And I'll occasionally do it during, around lunch too I'll get up and leave my office, cuz my office is windowless (laughs) so the day passes super quick without me having to see people and so I get up I get up quite a couple of times, probably about once every hour. Walk down, walk down to the opposite end of the building. Check my mailbox even though I probably checked it three times and then head back just so that I get a change of scenery.

(they begin to discuss windowless offices and unrelated information)

C: Alright. So I mean you mentioned that you've been doing this mind- I mean meditative walking, did you notice anything else that changed in your day to day life after the subsequent sessions? So we kind of talked about after the first one, what about after receiving all of your sessions did anything else change? 
E: Well. (pause) I don't know, I mean. The last three or four months or so I've been I've been trying to have a more laid back attitude. I don't eh I don't know if it has anything to do with the sessions. But I've been trying to be more, a lot more, go with the flow and less and um less having to schedule out my entire day. Cuz a lot of times I, while I don't schedule what I do with my kids outside of hey let's go do this, I schedule I schedule a lot of time I schedule my daily work from 8 until 5 um down to the hour. So that I know what I'm getting done, what I need to get done every hour, where I'm going what I'm doing and the last couple of months I haven't been doing that. And it's been slightly but I feel like I'm always missing, I'm always missing appointments like today. Because I normally keep a date book and my husband's trying to get me to use my phone's calendar and so appointments are spread out over both and I was like aaahhh and so I can't always remember you know do I have something? I can't remember! I agreed to watch so and so's class for them, what grading do I have to get done? I don't remember.

C: So it's getting to be a little bit of a struggle to remember certain things with the change up.

E: Yeah, so I'm hoping. I may just change it back, I shouldn't have messed with something that worked. It may be a little more time consuming and a larger thing to carry but my phone is silly and randomly goes off and you can't, if you have an alarm set that alarm will override your, your, your um volume level. (she continues to discuss cell phone volume controls...) I guess the thing that I've been trying to incorporate from the sessions is just being more mindful and in the moment. Because you know we had to spend so much time in our sessions with no stimuli. And so it was just, me and my thoughts and being in the moment and trying not to be focused on I have these five things that have to get done this evening. I I need, my brain wants to be anxious and nervous and overplan for them and I was trying not to, I was trying to do less of that.

C: Cut back on some of those impulses. So I mean tell me anything that you like, I mean anything you'd like for me to know that you noticed from the sessions. I mean does anything stand out? 
E: Um. I mean I enjoyed 'em it was just the only thing, that I had issues with is that they were so long. But that but that I mean I could have done with a thirty minute and I would have felt like I would have gotten more, it would have been a little more productive but I enjoyed them. I just felt like after that thirty 45 minute mark I felt eeeehh and she had to keep me awake.

C: Ok and you mentioned that before how you started to get pretty tired at that point.

E: Yeah and um, it was, I was surprised at some of the, the variety of each time we met. Um. Usually there was not only different issues that came up at each session but different feelings and emotions. Uh. Would have um she would do a full body meditative scan and each time there would be something different that popped up. Um we had one time where the in the scan without thinking about it I focused on uh one of my physical insecurities. And you know I wasn’t expecting to emphasize that or think about it. Um and then I think the part that I found the most unusual, and there was times that I mean it was still I understand why she was doing it but there was times that it was slightly distracting where she would repeat back to me what I would say and it would be a little jarring to hear my own thoughts repeated to me. It's not something that happens very often, normally you get input from someone else. Instead she would just reiterate what I would and so I would think about it a little bit more. Which was nice I mean a lot of times I would I would think about, I would, during our sessions I would have a lot of fleeting moments that something would happen and I would I would think about something and I would normally not revisit it but we would spend some time revisiting it and that made me more conscious and mindful of what was going on with me during our sessions. And so it just took a while to get used to it, that first sessions, was a little was a little um a little hard because everything was so different from what I was expecting.

C: Right right, I can imagine if that's not what you were expecting that would be very different. 
E: I guess I was expecting you know more like a fusion between a a regular yoga class and then um what happens when I go to my uh regular counselor because I I see for maintenance uh I go and see someone at the counseling um services in the student union about once a month, once every two months just to check-in because of the stress of being a grad student and being a parent just to keep um to help make sure that nothing is going awry.

C: So it wasn't quite what you expected in that way.

E: Yeah.

C: Um so what was it like to journal after the sessions?

E: That, that was probably the hardest part. My my unfortunately my journaling is I would say probably gonna be pretty sparse cuz there was a lot of times even within an hour of our session I couldn't remember what we did. Or what we were discussing what we thinking about and so I would try really hard to write down what what we had focused on or what thoughts had had come up but there was a lot of times I just honestly couldn't remember and I mean I always did it within within a day cuz usually I couldn't, our classes our meetings were usually in the late afternoon and so I couldn't get to it until the next morning um and it was, and so I don't know if it was because I just mentally dumped it (laughs) well cuz I mean that's a lot of time when I meditate that's what happens. You know I use meditation as a way to de-clutter and de-stress and so when I'm done meditating I feel free and fine and happy and everything's just ppppll and so she would ask me things like can you think of an I statement uh how would you incorporate such and such into your life between now and our next session and then the next morning, I mean it made perfect sense that day but then I couldn't remember the day after. And I'd be like uh I, we, we talked about this because I was stressed about that um I put my head on my head because I was stressed. But um what did we talk about? What was the actual I statement? It had something to do with rivers and being more flowy, flowy and strong like a river. 
C: So the journaling was not your favorite part it sounds like.

E: Yeah, I just I don't know, I've never been a journaler um and so it just didn't um it didn't come easily to me.

C: Yeah, that's understandable.

E: And so I tried really hard, I swear I did

C: Hey no judgment. This is a judgment free zone.

C: And so how does receiving this type of yoga therapy effect how you're currently living?

E: Well as I said earlier it's made me more mindful not only of what I'm doing or how I'm doing it but what I'm thinking about it because a lot of times I will either overthink something or underthink something and so it's made me try to really be more conscious of that middle road. And most importantly being in the moment because I have a hard time where I live either in the past or the future. Most of the time it's in the future. Worrying about this deadline or that deadline, worrying about graduation and finding a job. That job one always creeps up and is constantly there.

C: Yeah I understand that.

E: So that's that's probably what I took away the most out of it.

C: And are you having any thoughts and feelings after receiving the class sessions that you feel are pertinent for me to know?

E: I mean I wish I would have, I wish I would have done better at that journaling. Cuz I didn't realize until after all five sessions when I went back through the journaling that I just, that I was dumping all the information. 
C: Mm-hm right. So you kind of used that after session time to get rid of all the thoughts I guess and the purpose of the journal was to get some of those down.

E: Yeah so I just I spent, I was in you know I was so focused on being in the moment during our sessions that as soon as our sessions were over it became an afterthought. So I was spending all my time trying focus on um what I you know everything that I pushed aside for the session you know it would come flooding back in and so then I would be, the session would get pushed to the time until the next time I would be like oh session again!

C: Ok. So what stands out to you um the most about experiencing this project?

E: Um. I, you know I really, I really enjoyed seeing a different use for yoga. Because you know it's it's always promoted as just exercise. And so and I've been trying to use it for meditation. But I didn't I hadn't experienced it and so now I kind of know what I like. I like a little more movement, a little less meditation. I need it broken up into small bits um but I still thank that it was, it was very constructive and a worthwhile um aspect of my time.

C: Good. I'm glad you feel that way, I'm glad you kind of learned a little bit more about your yoga style and your meditation style.

E: Well and it's, I would say outside of, cuz the main reason that use yoga. You can tell its definitely not for exercise (both laugh) but it's to help its to help me with that being in the moment because when I do yoga everything else gets shut out and all I'm focusing on is the poses and how I feel about the poses and I feel about the music being played and so I I I use it and its principles to help get me through being in the moment with my children and with my husband and and not being so focused on the future that I forget what's going or I missed what's going on and I'm trying to be more um I'm trying to incorporate that more.

C: Ok. So being able to incorporate those aspects in other parts of your life. 
E: Yeah.

C: Alright. So what would you like to communicate to someone who's considering doing this yoga therapy? What would you tell them?

E: (pause) I would that it it, I would tell them that it's a great alternative to traditional therapy. That it can be more freeing than having to sit with a stranger and listen and have and and spill all of your issues and secrets. It's a way that can help you work through your own um your own baggage in a safe environment without being forced to over-share. It's more it's more self orientated. Or self led.

$\mathrm{C}$ : OK the next and final question was you know how does this experience or not compare to other healing modalities that you've been a part of or that you've tried? And you're kind of answering that with saying it's more freeing you know and it's more comfortable than spilling your guts to someone you don't know in the room and so you're answering that by saying that.

E: Yeah I mean,you know most of the time you know I will I mean I've only done these types of therapy. And they definitely, they have completely different goals you know when I go in and see the counselor for a mental health check-up I'm focused on telling him everything that has gone well everything that has gone bad, I ask for his opinions. It's more it's more of a conversation with someone else and that's the whole that's the goal that I've' set up for those sessions is I need someone to talk and work things out whereas for Jenilee's sessions, it wasn't, for me, it wasn't about that conversation it was more about being comfortable with myself and having an observer and working through things that I needed to work through alone. And so and both were both had their positive aspects you know, I would you know I could work through things alone that would be pretty easy such as stress over the dissertation you know she might give me a couple of prompts about it to pull it out but I would still be the one working through it, whereas working with the counselor I would be looking for him to give me feedback on the issue so I would say 
you know I'm having trouble with these students that I'm grading for, what do you think about it? And then he would give me his say and then he would say well what do you think it? And then I would repeat, I would say what I think about it and then we'd have a conversation about whatever was, very large issues that I needed a sound board to bounce off.

C: Right right. So definitely working with almost someone whereas working through by yourself kind of.

E: Yeah. Which is which what I do cuz I've always tended to do use meditation as a um outlet for when I'm alone um um especially walking if I'm really upset I'll go for a walk and I'll work through the issues myself. And so that was an extension, I saw this as an extension of that and then I just had an observer that would occasionally reposition me.

C: So using some of those tools in I guess a more controlled environment.

E: Yeah.

C: Well um that was my last question that I had for you and um I want to thank you for being part of the process. I know Jenilee really appreciates it.

\section{Katie Interview}

C: So I'm here with Katie and we're gonna go ahead and kind of get started with your interview regarding your experience with Jenilee's dissertation. Um so you know jumping right in um thinking on before like you actually did this, what was your reaction when you read the ad for participation in the study?

K: Um initially I was pretty excited. Um it wasn't just like I walked by and saw a flyer um I'm part of a group that Jenilee is associated with on Facebook and she posted the ad there and told us a little bit about the study. So I was initially pretty interested to get more information. 
C: Cool cool. So um were there any thoughts or feelings or experiences that made you pretty interested in becoming a participant?

K: Um I actually have an autoimmune disease and um I guess you could call it research if you will, I do a lot of my own um different research to see like what helps me and what doesn't help. Not a huge a fan of the choices that modern medicine has for the issues that I have. Um most of those drugs are chemo type drugs or they come with a really big impact. Um I tried that for a little while and it just didn't work for me and my lifestyle, so was looking for some more natural ways to help with pain and control symptoms. So initially that was really what struck me um was that this might be a good opportunity to see if I could learn something new or find some new ways to help with that.

C: Right right so maybe some new ways to make you feel a little bit healthier.

K: Absolutely.

C: Cool that's awesome. So what led you to volunteer what maybe kind of got you over that hump to say ok I'm gonna do it.

$\mathrm{K}$ : Um I'm one of those people that I'll generally try anything once at least. And that really has come about because of my autoimmune disease. Um if don't try it then the answer is always going to be no, the answer's always going to be it doesn't help because I didn't, you know, really give it any thought or didn't give it a chance. So when I spoke with Jenilee about exactly what she was doing um the, really the, assisted yoga poses really intrigued me because I have a lot of, I have a really hard time doing them myself. So even in a traditional yoga class I don't always get out of if what I would hope for so was kind of hoping that this would kind of be a step further.

C: Ok alright so how were these decisions making factors showing up in your daily life at this time, these kinds of aspects of yourself that..? 
$\mathrm{K}$ : Um for me they show up daily because it's kind of an ongoing battle, its every day is a new day but I still have the same the same issues so I have to um decide what things, some things work for me on some days and then don't on other days and sometimes that's just because of the activities I'm doing for that day, sometimes it's because of my emotional state or the way that I feel that day, um so I have to use a lot of decision making factors on a daily basis. You know I still work full time, I have kids, and so it's not an option for me to lay on the couch all day and complain. I mean I could but that would be a really sucky life. So um I just try things and if they don't work, they don't work and if they help then I've found something new and sometimes they only work for a little while and really that's all I need to give me a break.

C: Right. Yeah. So definitely going back to that try anything once attitude.

\section{K: Absolutely.}

C: So I mean switching gears to kind of your, thinking about your fist session, um what were some of the thoughts feelings an expectations that you had?

K: Um I'm not sure that I had any certain expectations for the first session. Um I try to keep a really open mind because I feel like that is something that is necessary when you're trying new things especially for me, because if I go into it with an attitude that its not gonna work then it generally doesn't work. And um so I try to keep a really open mind and try not to have any set expectations. You know I have lots of hope like I hope that maybe I'll get a little pain relief or I hope that I can learn some new techniques um you know to use in some form or fashion but overall I was really um, it wasn't what I even imagined it would be. Um which is you know is hard for you to imagine something that you've never experienced but it was completely different in a lot of ways than I thought that it could be. 
C: Right right. And I definitely want to touch on how it was different before we jump to that um were there any feelings that were associated with going into that first session. Or just um you mentioned um hope for you know pain relief, but anything else?

K: Yeah um I was probably a little nervous, I'm not a super nervous person but I mean that's kind of a big deal to open up to someone that you don't really know and um its also a big deal for me to um not just try something new but try it with like a new person and not knowing what to expect um even though I'll try almost anything once sometimes it takes me a little while to get there.

$\mathrm{C}$ : Ok, right right you like to wade in sometimes instead of jumping in ( $\mathrm{K}$ : yeah sometimes). $\mathrm{OK}$ so you mentioned that a second ago before I asked you that about um the you now experience was actually very different than what you were kind of expecting, so how was it different? What was it actually like?

K: Um the things that were majorly different for me um were emotionally, um I'm kind of a put together and like I can control my emotions pretty well when I need to and I felt like um that that Jenilee kind of cut that out. It was kind of like there was no need for me to do that. Um which really takes a weight off of me because when you're in pain all the time its really hard to keep your emotions in check so that's like something I have to work on. I have to consciously think throughout the day I'm not gonna fly off the handle, I'm not gonna snap at someone just because they don't understand what its like to be me. Um so when you take all of that work out then its kind of a completely different experience um and so I wasn't really expecting it to happen that quickly um and then also just like I said I didn't really have a whole bunch of expectation for how the session would go and I learned lots of interesting things um that I really didn't know would come up.

C: OK, um what are some of those things if you don't mind sharing? 
K: No um a lot of times I um when I'm doing like stretches and stuff I always think that its gonna be worse than it really is. Um mainly because I deal with a lot of pain um and so um pain for me is kind of like a reoccurring thing, it's the one thing that I know is going to be there everyday. Um and so when you get to a point where you realize its not always gonna be as bad as you thought it was gonna be, one that is like a weight lifted off your shoulders but it also gives you techniques that you can use when it is as bad as you thought it would be.

C: Right, ok, great. Um so did you notice anything in your day-to-day life after your first session? Any changes or anything?

K: Um after my first session I feel like I had a little bit of a positive outlook for the time that we were going to be together. Um I'm not sure yet that it changed a whole lot in my day-to-day life because I was still learning how to use what I was learning and I was still um you know like every session was a little bit different. I didn't always know what to expect when I got there um so I feel like from each session I took something different when I left. And so those different things definitely affected my day-to-day life but maybe not all at once.

C: Ok, alright. Um so you kind of said each one effected you differently, what did you notice as you continued to receive the sessions?

K: Um I definitely noticed different things from each session and outline some of that in the journal but really for me it was kind of like at first I started and had this really positive this is going to be awesome and I'm going to feel better and its going to work great, and then kind of exploring the feelings that you explore as part of the session. I felt like the second and third sessions were more negative, um dealing with negative feelings then um, maybe I felt more negative about myself during those session um, not, I guess not in a bad, everybody has negative feelings and that's something we have to explore and deal with, and I learned some techniques through those meetings um like things that I would be interested in trying or different positions 
that really helped with my pain that I could use when I felt really negative um but there was definitely like an emotional swing throughout. The sessions um started out on a really high note, kind of worked through some negative type feelings, and then came back and I feel like ended on a really high note.

C: Right, ok, alright, so kind of some peaks and valleys there. Um alright so tell me anything that you'd like for um me to know that you noticed and experienced throughout subsequent sessions um, like were they in terms of like the actual sessions themselves, you mentioned the positive and negative things, anything about positions or any differences in discussion?

$\mathrm{K}$ : Yeah um there were a couple of times where um I tried to learn to expect what's going to be next. Um because its one of my coping mechanisms, it's one of the ways that I know how to keep my emotions in control and I know how to deal with pain if that's going to be an issue and I noticed throughout the sessions that I feel like Jenilee noticed that as well and so then she would really change it up on me which I wouldn't necessarily, and you know she could tell like in my posture or whatever. And I remember specifically one session her saying so what are you thinking now? And I was like well I was thinking that isn't what I was thinking you were gonna do. Um and so just to kind of for me to realize that I do that, I didn't necessarily know that that was something that I did. Um and I as I look back and not only at sessions but at my daily life in general I totally do that. I totally try to plan for things that haven't happened yet because I'm trying to help myself get through them. Um and so that was I mean that was something that I noticed in different sessions. Like I guess that would be one main theme throughout several sessions is like I'm expecting these things to happen and then they happen and then I'm expecting these things to happen and they don't and then now I'm trying not to have an expectation for what happens next.

C: So kind of this acceptance that maybe you can't plan for everything. 
K: Yeah and I mean I know that I can't plan for everything. I know that things happens that I can't foresee happening and generally I'm a pretty go with the flow kind of person um its necessary for in what I do for my daily living um its necessary with kids because you don't really know what's gonna happen. But just as much as I can to protect myself like I cant just get up and go play a game of softball like it's just not possible for me anymore. Um so if I know that that's what everybody is going to do I would hate to be the only one that's going to be like sorry friends I can't go. So like I try to you know set for those things like prepare for those things, plan around those things um the best that I can.

C: Gotcha. Um so what was it like to journal after the sessions?

$\mathrm{K}$ : Um for me it was kind of therapeutic, I um that's one thing that I do regularly anyways is journal. So for it was easy to write just a few things down that I wanted to remember. Um or maybe even let a few things go that weren't as positive. Um that's just that's kind of what I've always used my journal for is um trying not trying to remember things that I want to hold onto and trying to let go of things that I don't need.

C: Right. So just an extension of what you were already doing essentially.

K: Basica..well a little bit different. Like I'd I basically focus on the session and um how they made me feel and things that I noticed. Um but then like in m daily life journal it's a little different.

C: Ok, alright. So this is just more specific to the sessions.

K: Yeah. Absolutely.

C: OK. So how has receiving this treatment effected how you're currently living? 
K: Um well I think it's affected me in a couple of ways. One, the assisted yoga positions was something that I really enjoyed. Um and it's something that I have continued to do. Um so for me part of it is that I can control the positions that I get in and out of and part of it is that I still need someone to help um and so um that's something that I plan to continue to do for a long time. Um. And hopefully um as I go through it and do it more then I'll have some better um mobility and flexibility and be able to do some things without assistance. Um but until then I got something.

C: Right definitely definitely. And you said there were a few things so kind of continuing the assisted positioning and?

$\mathrm{K}$ : Right and then the rest is probably more mental, emotional. Um like I said I learned some things about myself that I didn't really know or I was ignoring. Um and you know emotionally and well both emotionally and mentally I kind of opened some doors. Um. It helps me understand some of the coping mechanisms that I choose to have, it helps me to understand um what maybe a better choice in a coping mechanism would be. Um basically just learning a little more about myself.

C: Yeah. OK. Well that's good I'm glad that it was able to do that for you. Um so what are your thoughts and feelings about this type of treatment modality now that you've received five sessions of it?

$\mathrm{K}$ : Um I think that it would be a great, I think that it's a great modality to have. Um. You know in nursing we do lots of treatments we do lots of modalities. Before I was a nurse I was an athletic trainer so we did things that way too. And I've never done anything quite like this. Um so I definitely feel like there's not something um at least here we don't have that option. Um and that this could fill some gaps that other modalities have. Um. I noticed that it especially um helped with the time between my chiropractic adjustments. I felt like it really lengthened the time between before I felt like I needed a new adjustment. Which is a big deal for me. And um I feel 
like all modalities are not right for one person, which is one of the reasons I said I felt like I was looking for something new in the beginning anyways. My sister, and we both have the same autoimmune disease and what works for me does not necessarily work for her. Um we live different lifestyles. She's 8 years younger than I am and so she's in college and um doesn't have kids. Like I have a whole full time job and kids and um the things that worked for me when I was in college are not the things that work for me now. So I'm just understanding that when we have new modalities available, they're gonna help some people. They might not help everyone but people wouldn't be looking for something new if what we had was working.

C: Right. So what stands out most to you about this experience?

K: Ummm. Really there's a specific conversation that Jenilee and I had that really stands out. And I mentioned a reference to it earlier and it has to stood out since the. I mean since it happened basically, and that was when you know I really didn't expect her to change it up on me and then when she did it wasn't as bad as I thought it was gonna be. Um and so it I kind of learned some things about me like I said earlier but then I also kind of learned some ways to um put things into play or into practice um like maybe I shouldn't be as hesitant, maybe I shouldn't always wade in, sometimes I can jump in and it will be ok. And like I said things will work and things won't work um but that specific conversation has really stuck out for me because that's the one of things that I feel like I need to work on personally.

C: Right, ok. Um so if someone else was considering doing this type of therapy what would you most like to communicate to them?

$\mathrm{K}$ : If someone was um considering this I would really just try to communicate to start with an open um and to keep your open mind as best you can throughout the sessions. Um I feel like those times that I was truly open um to whatever we were doing um to what we were talking about those are the times that I really got the most out of it and those are the times that I learned 
the most about myself and about things that I am hoping to know about the future or to put into practice for the future. And so don't have any expectations, don't expect it to go one way, just go in with an open mind and a clean slate and see what happens.

C: Cool, great. Great great great. So last question, um, how does this therapy modality compare or not compare to other healing modalities that you have received?

$\mathrm{K}$ : Um because everything is so different I generally don't compare them to each other. Um for me in um this modality worked better than several others that I have tried but there's nothing really like this. There's nothing that I have done that is the same. Um so I guess I would say that its unique and that it opened my eyes to several things that I may not have thought of before, um and that I did see success whereas there have been other modalities that I have tried um that didn't really do anything for me.

C: Great, great, alright. Well I want to thank you for giving me some of your time.

\section{Sally Interview}

C: Alright. So um thanks for joining me I appreciate it. And I'm sorry about the weird parking meter and moving over here. I know it's a little wonky and that spot can be hard to find too.

S: Well and this gate down here is new. It used to be a guard shack when I went to school here and there was a person that you just told what you were doing.

C: Oh alright. Now I'm pretty sure it's just buses during business hours and stuff like that so that's fun.

S: Exactly. Exactly.

C: So if you're ok with it we'll just kind of jump right it, 
S: Ok.

C: Alright.

S: Yeah I think we're already behind in time.

C: No no no no, you're fine. I just want to be you know cognizant of what you've got going on today. Um so the first question we kind of have here is you know, what was your reaction as you read the ad for participation for this study?

S: That's a great question. Um I don't know. I guess, it had yoga in the name so it was attractive for that reason. (C: Right, right) I didn't know what it was about but I have participated in a couple of other studies this year and so I thought I might as well try it.

C: Alright. So kind of this interest in these other studies really helped you into this one?

S: Yeah, just being outside my comfort zone of being recorded and that kind of thing. I did uh a interview with a friend who was doing her dissertation, for her dissertation. And then I did an um interview with another friend that was um writing a paper. So I have those, audios of those. For posterity, put it in the time capsule.

C: Oh ok gotcha. That's cool, that's neat.

S: Yeah. That's pretty interesting.

C: So it sounds like yoga is something that you enjoy.

S: Definitely.

C: Ok, cool. So um what did you notice about your thoughts and feelings and experiences as you considered becoming a participant? What was going on inside? 
S: Um I would say, being as it's an artificial experience because it's a study I can see where it would be really beneficial if you had, were not being recorded and were not in a study, I could see where it's really beneficial even though it's not really a therapy because their Rogerian, my favorite my favorite guy, I read about it later and found out that, that makes sense that it seemed unconditional positive regardish. But I would say I could see where it would be beneficial in the future. Or in real life. But in a study I definitely wasn't um interested in getting into anything really major because it was a study but I could see where it would bring those things up.

C: Ok so there was a sense of holding back because of the fact you were being recorded for a study.

S: Yeah, not really holding back, just not I fully experienced, I journal myself and so I fully experienced it myself, but I just as far as what I want would want to bring up or start up for a whole for 5 sessions and then it ends that's impractical. But I could see where it definitely got me thinking about stuff that I wouldn't usually, that I had buried.

C: And did you see any of that coming when you considered being a participant for this?

S: No, no just um I thought it would be, I thought it would be interesting to find out what it was about and I do, I do yoga and I do Egoscue and I have always you know done self examination and so I thought it would be kind of a combination of those, and it was. It was very, it was very cool

C: Good, cool cool, I'm glad that you liked it.

S: Yeah.

C: Um so what led you to finally volunteer as a participant? 
S: Um I just um volunteered and I was one of, I think she had 6 people and I was one of the second or third people to accept the offer or whatever. What led me to not quit maybe or not you know um you after we had our first discussion about it, was probably just how Jenilee is, she's a very welcoming and unconditional person, and very um calming.

C: Right. Ok. So her presence kind of helped you out a bit with being comfortable with the study.

S: Yeah well she's clearly an expert at that. Maybe that's just how she is or maybe she's developed that anyway but she's very good at it.

C: Good good, I'm glad that was a good thing for you. So how were these decision making factors showing up in your day to day life at this time?

S: Decision making factors on..?

C: Like the things that led you to participate are they also how you kind of live you day to day life like?

S: Yeah, um this last year, couple years I guess um I have decided to do things that I wouldn't normally do. I'm not going to jump our of a plane or anything but just things that are uh that have been, I've been reticent with before, I'm just more open to trying new things and one thing uh that's starting up actually in September again is the yoga in the garden and I'd never done yoga outside before and it's free and it's at the botanic gardens and so it's gorgeous and that's something that's ooo in front of people and I don't take, I've taken one yoga class a long time ago, a friend of mine started teaching them and offered a free class to people and I like to practice by myself and so that was an interesting difference and then those two studies, just being able to share myself um that's new like in the last couple of years. Um so I just think its great, it's a good cause too. It's, research is always a positive thing. 
C: Yeah, it definitely I would agree with that. And you said this kind of new attitude you've been taking on has happened in the last two years.

S: Yeah.

C: Is there anything significant to the last two years or specifically or like a starting point to I'm going to do these things.

S: Um not specifically no. I mean I've experienced a lot of family members die, different people that were close family members. Just kind of a wake up call of hmm you know this is finite, finite space and time and so just that that was and I went to a conference right before I started with Jenilee. Well I think I met her and then I went to the conference and then I had a first session is what it was. And it was a grief conference and it was really validating because um the first person that died was my brother and sibling is disenfranchised grief because everyone asks how's your mother and um. There was even a session called how's your mother for siblings because its so common. And so that, all those deaths was like being pushed under as soon as I'd get some air and then someone else would die and then so I got, after the last person died in 2012 I got back on my feet and decided that's gonna do things differently. Not that I've had a bad life or anything but just being more open to new experiences and trying new things.

C: Right and (inaudible) so when you started to kind of see the finality of something or of life, I really get that. I need to pause for just a second because I have a really really bad feeling about something, oh alright it's on (conversation about microphone being on ensues....)

S1 My first session with Jenilee was right after I got back and I was really raw. I mean I was energized and charged up and everything from being validated and being with a group, in a room of 50 siblings all who had lost their sibling was just phenomenal but there's also a let down or kind of a grief hangover after you leave something like. And it sounds awful, there was a community in there that said he wrote his grief joke that was just uh so I'm going to a grief 
conference this weekend and he goes there now you have something to say to make someone just walk away because they won't to talk about it because they'll be like awkward. So that's how when you get back, I mean I can talk to my husband and kids they're very supportive, but there isn't much support about that experience and being able to debrief about it. And so I went to, because I'm normally very silly and happy and fun um you know no bitchy resting face so like that, but I don't know that was really tough but it was great. And so coincided really well with the therapy because it um the idea that she would care enough about humanity to bother to do this is like amazing to me. You know. There's not very many people that do that kind of stuff. So.

C: So again kind of this idea of you know Jenilee caring or Jenilee's presence really impacting you in this moment.

S: Definitely. Yeah.

C: That's great that ya'll were able to form that bond. Um so what were your thoughts and feelings and expectations as you arrived for your first session?

S: I just assumed it would be talk therapyish but I didn't know it was the repeating back what you say thing. And at first that's super annoying, and not that she's annoying, but that's just a weird thing because when you take conventional therapy um instruction they, they help you learn how to mirror back what someone's said but not use their exact words and their exact you know if they say um or er or you know but that was odd. But then it became later I realized that when I meditate everyday in the morning first thing for 20 minutes completely silent that I should have my thing on because I think all these thoughts and then their all gone when I get done at 20 minutes I cant remember all those that were really profound. Kind of like um you know edible trash or you know whatever ideas you'd want to write down that you can't. And so that was interesting to have someone else even though it was personal and it was private information it was interesting to have someone else repeating back what my thoughts were. And even when she 
would, I would say uh huh. Like I just said hat but I'd still agree with her because it I don't know it was interesting but I didn't have any preconceived ideas I just assumed it would be talking where she would say well some people find this helpful or you know and it wasn't like that. Then I read a little bit about to just figure out like what is it and then I figured out ok I understand it better. And so I want to have an after party with all the people that were in it just I don't know if I can but anyway. I would love to like get together with them and exchange notes on what they thought because it's something very unusual for Stillwater or even OK I guess.

C: It's interesting that you mention the geographic kind of area I guess because you know a lot of people may not think about the space that they're in necessarily.

S: Yeah you know this place, I've been here since ' 85 so I'm kind of now from here but I came northern Indiana and this is a very odd environment. I'm vegan and its beef is what's for dinner license plate, I don’t have ne of those weirdly. But you know its just different and people yoga they think of it as kind of weird. That's what people do in CA or something and then therapy no way. Keep your feelings in you know, or drink 'em down. This is just a different culture I think. I don't know. She's not staying here I suppose but I think it's needed everywhere. This kind of thing is needed everywhere so hopefully there will be you know some form of this. I know she said in OK city there might somebody so.

C: Alright. So it sounds like you're quite appreciative of just the experience given like that we're in Stillwater.

S: Yeah, it's very unusual.

C: So you said it was interesting having Jenilee saying those exact words back to you. Were there any gut feelings or reactions to that besides just oh that's interesting or..? 
S: Well, oh that sounded really dumb or oh that sounded really profound. You know just depending on what it was because everything you say is repeated and so and the also tell me more about it and those types of things happen. So there's plenty of I mean you could be silent as well. I didn't always share what I was, clearly I couldn't share every thought I had but I didn't share what was like my intention, I didn't do that. And she actually said that she appreciated that I didn't do that. Which is pretty outside the box because if I was her I'd want to know everything that was being thought. But sometimes it was just like I started out with an intention but the end intention, because you do it at the beginning and the end, anyway.

C: OK so kind of switching...the first session you kind of spoke about how you actually experienced your first session. Is there anything else you'd like to tell me about that, how you experienced that first session?

S: Oh just like I said just really emotional and that was right out of the conference. I think I got back Sunday and it was on Wednesday that I saw Jenilee and I like slept all day Monday. I mean not all day but I really was very busy from Thursday though Sunday so I was really emotional and it isn't that I don't want to be emotional, it's that you know I I get it, that all these people are gone. But it's when you really spend a lot of time like I don't know. You cant compare someone's grief to someone else's grief ever but I do (inaudible) think I am fortunate to have my brother as long as I did because I met a lot of people that had their brothers and sisters shorter or died in a more horrible way, you know, so I was in I was having all those types of things that first session just kind of going over all the things I saw. It was very um emotionally intense. And so that I think that was my experience the first time.

C: Right. So this this grief conference being so fresh definitely framed how you were experiencing this session. 
S: Yeah it did. And you know by design because she said when it as starting and I could have said well I don't want to do it for two weeks after it or whatever. But I wanted to do it every week in a row so we managed to do that.

C: Alright. What did you notice in your day-to-day life after receiving your first session?

S: Well I was surprised I wasn't sore and uh and Jenilee is extremely strong so I expected to be sore. Um uhh I guess just that I did it like yay I did! And I finished the whole thing and I didn't go oh you know this isn't for me. So I guess that was what my take away was the first time.

C: Ok. And um what did you notice in your daily life after you or as you continued receiving sessions?

S: Uhhh well I was very busy. I'm not normally busy at all but I had signed up for all these grief counseling things because I wanted to start a group in Stillwater and so I was going to four different um grief groups all in those couple of months that I was seeing Jenilee. So then I was also moving I have an office and I was moving my office all the way to a new location, all the stuff and getting all setup. And so I was just insanely busy and so it helped me slow down because when you first check-in you literally check-in with what are feeling and what are you thinking? And I realized that I could that anywhere. I do do that actually when I meditate in the morning because I start no matter how busy my day is, even today I made sure that I had all the time that I needed before this and then I have something after this and something right after this so I made sure I had that because I think that's important to make sure I have that, to make sure I can check-in. But I think that was made clear that I could do that.

C: So um sounds kind like you're you were able to take some of the mindful aspects.

S: Definitely. 
C: Alright. So then tell me anything you would like to that you noticed or experienced throughout the subsequent sessions. Anything at all. Very broad.

S: Um that I liked about them? (C: Mm-hm.) Um variety and I don't know if that was by design. Of course I'm dying to quiz her about every part of this but she needs to finish her dissertation first so that I don't spray it with crazy. But every one of the times we met it was all different except for the beginning and the end. And I was like surprised I was like wow there's a lot you know. And I know that from yoga and I know that from Egoscue, those both have thousands of exercises technically. But I was really surprised at the variety and also the individuality of it. Because I mentioned like one of my shoulders, like this hand can't go all the way back and this one can. And so she worked on this shoulder just by like automatically just like knew that would be a good idea. And uh trying to think of what else. I'm definitely going to um figure out a way maybe I can bribe my kids or my husband but some of the traction moves or positions were really therapeutic and I was pretty surprised by that. I don't know if there's a good safe way to do that for yourself. I mean a system of ropes and pulleys or something. But um I said that I clearly need her to be at my house when I'm doing yoga because then she could expand the pose more so cuz its just its different than yoga what she does because it's yoga and then plus, plus um so it's different.

C: So the tractions kind of helped you extend your poses?

S: Definitely. And it wasn't really poses because I was on the floor the whole time but it like stretches the smaller muscles and the smaller connective tissue because a lot of times you just do everything with your giant muscles, you don't do anything with the finer ones that are like skeletal or I mean spinal or whatever. Anyway. But it was just really nice. 
C: Right and how did it interact with the talking? Did you notice any like I guess any significant differences or anything like different than just your traditional talk therapy?

S: Well completely different because there's no, well not that traditional talk therapy gives you solutions because typically they are just taking what you say and helping you see that you already have the answers like that's the secret code. But Jenilee doesn't give you any, like if she said tell me more and I write down every time she said tell me more I might go ok those are some important things I said. But it was just like reflecting everything I said. Like I said it would be like if I recorded my mediation and when I thought about a way to keep socks together in the laundry or something random like you think because thoughts go by like a moving sidewalk in the airport and you just go hello thought like you don't necessarily keep thinking about it. If I wrote down all those it might be interesting so what I did was as soon as I was done with her I went out in the car and wrote as many notes as I could possibly think of before I drove away. Because I, I love writing and I love like details and analyzing stuff so I did that and so that um. I, it would've, I would've been disappointed if I went through this five sessions and was like yeah it was fun you know and that's all I had to say about it.

C: So definitely kind of taking an intentional lens on like how you experienced this and how youS: Yeah exactly.

C: Alright. Moving on to the back. Um so what was it like to journal after the sessions?

S: Oh it's great I mean I do journaling anyway I write you know 4-10 pages a day. So it wasn't, it wasn't difficult for me. I thought later that I should have drawn some pictures to make it more fun but of course I didn't so just wrote words. But uh there, I, I have a couple of people that are really interested in what yoga therapy is and so I also wanted to be able to tell them poses so I wrote those down after I got out there but I don't, obviously I don't have a um map of that I just have my memory from right afterwards. And so I would uh add to my journal later when I would think 
of oh yeah there was one other thing she did, was I stood on my head or whatever and then I would add to that. But I really enjoyed, I suppose if you weren't someone that wrote every day you might find it like oh god what do I write about? Because it might be kind of difficult but I don't know.

C: But since you write everyday-

C: Yeah, it was easy for me. And I wrote in my own journal you know I didn't necessarily write what I thought about. You know just like I would have my own thoughts about it also that I would write about.

C: Right right, ok. Kind of went above and beyond.

S: Yeah, it was fun.

C: So how has receiving this service affected the way you're currently living?

S: Um, well, hmmm. I guess I mean I definitely would recommend it to people and um like I said if it was real life and you had a person that you saw every week that might be, that might be nice. And also Jenilee is very approachable person so she isn't uh (pause) she is like, she checks in to find out that the edge that you're at and I don't know how familiar you are with the, the whole thing. Well like if you're like laying on your stomach and she your ankle up in that corner and she's like gonna put it up at the ceiling she's like how far are you going to bend your leg completely. I don't know how she did that because this is not a small leg. But she would say you know tell me when it's good to stop or whatever. So like lots of feedback and you know she's also not in character perfectly all the time to where she's unapproachable. Like when I said I was giving birth to a pain baby, she laughed or whatever because it's not, you don't, because sometimes when you're with a person, medical practitioner, therapist whatever, they're like very stiff, they won't smile they won't giggle whatever, they're like the Buckingham palace person 
with the chin strap. But she's not like that. So I felt like ok to say what I was really thinking. And it's interesting to have your, you have your eyes closed the whole time. And I already do that. That's one of the ways I got through the first few times of yoga in the garden because I'm like I'm not with a bunch of people I'm alone and the delicious smell and the breeze and try not to obsess on. Because like in yoga you're not supposed to compare yourself with others or whatever and so with um with Jenilee you keep your eyes closed the whole time and so um the focus is just in. In the now. And that's something you're hardly ever doing in your life. You can't do it while you drive because like that would be fatal but you can't really be in the now almost ever. And when you shut your eyes you're in the now a lot. And sometimes you know you're in the past because you'll have a thought but I mean you're still like in the room. So I thought that was helpful.

C: great. So what are your thoughts and feelings about this type of therapy now that you've received five sessions? Um you said that you'd recommend it-

S: Yeah, I'd definitely recommend it. I would recommend it and also um not necessarily you know in a study and like I said being filmed. Like that's kind of creepy. Um hmm. I mean my husband sells cameras so you know I know what kind, I'm just saying the we joke around that we can't scratch our butt in the yard because there's but he has the you know motion activated and whatever and so it's not like and I was, he had one hooked to a gym that we have and like a pulley thing we have in the house and I was like that will need to come down and he was like I'm just testing it. But we don't have any in our house. But it's just a weird big brothery thing to be filmed. So that was kind of like, that was off putting. I'm not sure that it's off putting to everyone but it's off putting to me at least. And I also told her on the thing that I didn't know that the exit interview was recorded because but it was on that thing I signed so yes it was. But uh I didn't know it was because I assumed it was a place to say how damaging that was that experience was really hard on me or any of that stuff. I know I can still do that but I mean she's gonna hear it you 
know what I mean so that was weird so I had to get past that because its all me, its all my own perception of being recorded and stuff so. Anyway. So that was my experience.

C: Alright, alright. Um so what stands out to you most about your experience participating in the project as a whole?

S: Um. I guess that I finished it. And. It's. Uhhh. It's just another um step outside my comfort zone that I completed and didn't quit.

C: (pause) Yeah that (S laughs)

S: She'll have to get you on the mat.

C: Oh I've been on it.

S: Well I mean for the yoga therapy. That's like oh my god!

C: Yeah it feels good.

S: Yeah it feels interesting.

C: So what would you most like to communicate to someone who is considering this type of therapy?

S: Well I would say one of the key things for me was that you like I had a memory of effortlessly doing a backbend on the balance beam as a child and then my legs flicking over and stuff and when I'm in like a bent over the ball pose I had, you're not uh I don't believe your body stores things 'cuz that's kind of like biologically not true but your mind has memories that are associated with positional qualities of your body and so like when she had the um yoga belt buckles she gleaned around you know, I've been beaten with a belt many many many many times and that was like gheeee really nerve wracking and so I had to fight to not just open my eyes and say wait what are you doing put that down. And I had to remember that it was her and I had to 
remember where I was and that I was safe and that I'm 54 years old and I can you know fight for myself and those types of things. But I think that's why it's helpful. So if I could explore that more that would be where like I would go into those memories or I would go into maybe other types of memories that come up, good and bad, because I'd love to be as flexible as I was when I was you know 10. And you lose that flexibility so easily. Just you know everything you do is in this box, you know you type and you prepare food and you wash dishes and you drive and you don't ever extend yourself completely back like and that's why its different because that was like the play of childhood. I didn't do gymnastics because I wanted to be a gymnast I did it because it was fun. And so I think that yoga therapy brings up pain and then it also brings up really fun memories. So both of those.

C: Ok. Alright. So how has his um you've spoken to this some of this too. But how has this compare to other healing modalities that you've experience.

S: Um I, I mean years ago, I went to counselors and stuff and it always was awful and they were terrible at it and it didn't help at all. And the truth is now I know is that you have decide for yourself to change and you're the only that can actually help you change and stuff like that. So that's why this is kind of ideal because it's physical and it's emotional but its coming from my mouth and just being repeated back to me. So it's not even, like if could get someone to do all that and then just a machine was saying the words back to you it doesn't really have to do with, she, it does have to do with her intelligence and her intuitiveness and all that too but with her to say tell me more and all those types of things. But that was very different then just talking to someone and then them saying well maybe your parents are right or maybe you should be nicer to your teachers or you know. The blaming of therapy and just I don't know. And I don't, other than that, that was years and years ago. I have not been to anybody for anything for you know probably 20 years, or more than 20 years because my kids are 20 and 22 so provably I don't even know. But maybe 1985, '87. So because it was so awful. So and you know when you go to school 
to learn about being a counselor or being a helping person, there's a lot of people that want to stay in the problem and they're stuck there and they just want to whine about it and so maybe that's how I was to them. You know I don't know. But this is different completely. Its got a different quality to it.

C: Ok that quality being the uh-

S: Just yeah that it's yourself. And you know I don't know who she had in the study specifically you know because that's anonymous but the people that if they do yoga before they came to it or they didn't do yoga before they came to it it's all accessible. Like you didn't have to have a level that you were at with physical strength or flexibility. And then like mentally like I said it was weird the repeating thing. But when I looked it up I was like ok that makes sense because it's Carl Rogers so that's obviously. That's the way it should be is, if everyone had unconditional positive regard for everyone else there wouldn't be any problems at all. Like it would just be perfect. Like so I think it's accessible to anyone. But like other kinds of counseling you often hear people say well I tried that but it was awful. And it's expensive. So that's another thing that it was free, if I had to pay to be in this then I don't know what my thoughts would be. You know, like a dollar a minute that's what I'm assuming because its like massage or something like that.

C: OK. Well thank you so much for your time. You've reached the end.

S: Yay!

C: So you've officially finished everything.

S: (talking about a sticker from mini blinds) So the other thing too is that it made me realize that I could potentially, not making any promises, go and get a massage. Because the thought of anyone touching me is like creepy and uncomfortable and awful. And so um that was something that she was very mindful of because we talked about it beforehand and she would tell me where she was 
in the room 'I'm moving over here, I'm going to be put my hand here. And so um my friends that gets massages all the time said that she was like screaming and jumping up and down with her phone when I texted her that I possibly might do that. Because she's like your'e gonna love and I was like ew. My husband and my kids like I'm very physically affectionate with them. But um strangers yeah. Ew.

C: Wow so this did have a big impact on you it sounds like.

S: Yeah it did. Well it did because I, us 4 kids, were molested by our pediatrician, so there's no grey area to me with people in my space. Yeah. And so it you know, even in like toast masters we shake hands but then some people but their hand on your back and like yeahhh, so you know I think this will be helpful in a lot of ways for people. And I was thinking of posttraumatic stress disorder people as well because you're, you know the kind of people that won't open up unless they're doing something physical so you know you can have a conversation with them and they're not really very. But then if your painting or something or you're driving somewhere and they're in your back seat and then they open and that's kind of how this is because its distracting you, your body's doing something and then you're accidentally saying things, well not accidentally but you know. Those are all my secrets.

C: Well I appreciate you sharing all your secrets.

S: It's not, well I've dealt with most of them. But you know, anyway, it was a great experience.

C: Thank you for meeting with me and being vulnerable with me for a few minutes because I know you don’t really know me. 
VITA

Jenilee Sneed

Candidate for the Degree of

Doctor of Philosophy

Thesis: PHENOMENOLOGICAL INQUIRY INTO PHOENIX RISING YOGA THERAPY

Major Field: Educational Psychology

Biographical:

Education:

Completed the requirements for the Doctor of Philosophy in Educational Psychology with an option in Counseling Psychology at Oklahoma State University, Stillwater, Oklahoma in August, 2017.

Completed the requirements for the Master of Arts in Counseling at Ball State University, Muncie, IN in 2009.

Completed the requirements for the Bachelor of Arts in Psychology at University of Redlands, Redlands, CA in 2006.

Experience:

2016-2017 Butler University Counseling and Consultation Services- Predoctoral Intern

2015-2016 Oklahoma State University Counseling Services- Intake GA

2014-2015 Oklahoma State University Counseling Services- Practicum

Counselor

2013-2014 University of Central Oklahoma Counseling Center- Practicum ` Counselor

Professional Memberships:

American Psychological Association

American Psychological Association Division 17- Counseling Psychology 